\title{
SARS-CoV-2 therapeutics: how far do we stand from a remedy?
}

\author{
Anurag Sing ${ }^{1} \cdot$ Vandana Gupta $^{1}(1)$ \\ Received: 19 August 2020 / Revised: 20 November 2020 / Accepted: 29 November 2020 / Published online: 3 January 2021 \\ (c) Maj Institute of Pharmacology Polish Academy of Sciences 2021
}

\begin{abstract}
The SARS-CoV-2 has affected millions worldwide and has posed an immediate need for effective pharmacological interventions. Ever since the outbreak was declared, the medical fraternity across the world is facing a unique situation of offering assistance and simultaneously generating reliable data with high-quality evidence to extend the scope of finding a treatment. With no proven vaccine or other interventions available hitherto, there is a frenzied urgency of sharing preliminary data from laboratories and trials to shape a global response against the virus. Several clinical trials with investigational and approved repurposed therapeutics have shown promising results. This review aims to compile the information of the reported molecules approved for emergency use and those under clinical trials and still others with good results in the studies conducted so far. Being an RNA virus, SARS-CoV-2 is prone to mutation; thus, the possibility of gaining resistance to available drugs is high. Consequently, a cocktail therapy based on drug interaction with different stages of its replicative cycle is desirable to reduce the chances of evolving drug resistance. Since this virus encodes several proteins, including 16 nonstructural and 4 structural proteins, this review also offers an insight into potential drug targets within SARS-CoV-2.
\end{abstract}

Keywords Antiviral $\cdot$ COVID-19 $\cdot$ Drug repurposing $\cdot$ SARS-CoV-2 $\cdot$ Target proteins

$\begin{array}{ll}\text { Abbreviations } & \\ \text { 3CLpro } & \text { Chymotrypsin-like protease } \\ \text { ACE2 } & \text { Angiotensin-converting enzyme 2 } \\ \text { ARDS } & \text { Acute respiratory distress syndrome } \\ \text { COVID-19 } & \text { Coronavirus Disease 2019 } \\ \text { CQ } & \text { Chloroquine } \\ \text { HCQ } & \text { Hydroxychloroquine } \\ \text { IFN } & \text { Interferon } \\ \text { MERS-CoV } & \text { Middle East Respiratory Syndrome } \\ & \text { Coronavirus } \\ \text { Nsp } & \text { Nonstructural protein } \\ \text { ORF } & \text { Open reading frame } \\ \text { RCT } & \text { Randomised Controlled Trial } \\ \text { RdRp } & \text { RNA-dependent RNA polymerase }\end{array}$

We do not recommend these drugs to be taken without a valid prescription. Guidelines from regulating authority must be followed strictly.

Vandana Gupta

vandanagupta72@rediffmail.com;

vandanagupta@rla.du.ac.in

1 Department of Microbiology, Ram Lal Anand College, University of Delhi, Benito Juarez Road, New Delhi 110021, India

$\begin{array}{ll}\text { SARS-CoV } & \begin{array}{l}\text { Severe Acute Respiratory Syndrome } \\ \text { Coronavirus }\end{array} \\ \text { SARS-CoV-2 } & \begin{array}{l}\text { Severe Acute Respiratory Syndrome } \\ \text { Coronavirus 2 }\end{array} \\ \text { TMPRSS2 } & \begin{array}{l}\text { Transmembrane Serine Protease 2 } \\ \text { Randomised Evaluation of COVID-19 } \\ \text { Therapy }\end{array}\end{array}$

\section{Introduction}

Very recently, in December 2019, a novel coronavirus, now designated as Severe Acute Respiratory Syndrome Coronavirus 2 (SARS-CoV-2), triggered a pneumonia outbreak in Wuhan, China [1], and since then has spread rapidly across the world. This outbreak was declared to be a "pandemic by the World Health Organisation (WHO) on March 11, 2020". SARS-CoV-2 belongs to the same family of viruses as Severe Acute Respiratory Syndrome Coronavirus (SARS-CoV) and the Middle East Respiratory Syndrome Coronavirus (MERS-CoV), which caused outbreaks in 2002 and 2012, respectively. According to Johns Hopkins University and Medicine Coronavirus Resource Center (https://coronavirus.jhu.edu), there have been 56,901,880 laboratory-confirmed cases with over 
$1,360,408$ deaths in more than 191 countries/regions worldwide as on November 20, 2020. With approximately 100,000 new cases appearing every day since May 15 which has increased to approximately 150 thousand by June 19, 2020, we are still in the middle of a pandemic, heedless when the downside of the pandemic will begin. COVID-19 (Coronavirus Disease 2019) presents with symptoms like fever, cough, fatigue, phlegm production, hemoptysis, headache, diarrhoea, lymphopenia, and shortness of breath, appearing after a mean incubation period of about 5.2 days. These could be mild or asymptomatic to severe ones progressing to pneumonia and other complications like Acute Respiratory Distress Syndrome (ARDS) which could be fatal, especially in older patients with comorbid conditions [2-5]. ARDS might result from 'cytokine storm' which occurs due to the release of large amounts of proinflammatory cytokines, including interleukin-6 (IL-6) and tumour necrosis factor-alpha (TNFa). ARDS was also presented during the SARS outbreak, wherein during endocytosis of SARS-CoV, ACE2 receptor gets simultaneously endocytosed, leading to reduced ACE2 on the cell surface. ACE2 is an inactivator of angiotensin 2 (AngII) and the former's reduced concentration leads to increased levels of AngII. AngII is not only a vasoconstrictor but also a pro-inflammatory cytokine [3, 6-9]. Thus, effective treatment of moderate cases is desirable to prevent progression into severe ones, to reduce the overall mortality rate.

In the absence of either the approved therapeutics or any effective vaccine against SARS-CoV-2, we completely rely on an individual's immune system to clear the infection. Strict isolation norms and extended contact tracing can help in what we call 'flattening the curve' and, hence, prevent the healthcare system from being overwhelmed. As of November 20, 2020, the worldwide fatality rate stands at $2.39 \%(1,360,408 / 56,901,880)$ and varies greatly in different countries. China, where the outbreak was recorded first, has $5.15 \%(4742 / 91,935)$ fatalities; the USA has $2.15 \%(252,555 / 11,717,827)$, India records its fatality rate at $1.46 \%(132,162 / 9,004,365)$ and most of the European countries recorded higher fatalities. Rate of fatality varies widely in different territories across continents with lower than $1 \%$ in the middle-east to higher than $9 \%$ in Mexico (https://coronavirus.jhu.edu).

There could be many effective therapeutic targets within the life cycle of SARS-CoV-2 including:

1. Blocking the viral attachment to host cells by disrupting bonding between viral cell attachment proteins and the cellular receptor, and inhibiting Spike protein cleavage by the host TMPRSS 2 which stimulates the formation of endosome facilitating virus internalisation.
2. Inhibition of transcription, translation, and replication of the viral genome.

3. Stalling the assembly process by targeting structural and nonstructural proteins critical in viral assembly.

Coming up with exclusive drugs for clinical presentations takes years of effort and billions of dollars ( $\$ 2.5$ billion) $[10]$ in investments. Time constraints posed by a sudden and novel pandemic makes it almost impossible to propose such novel molecules by conventional protocols. Thus, efforts to explore off-targeting of already approved molecules remains the only hope to possibly provide an answer. Drug repurposing saves the precious time and money in the development, formulation and the subsequent phases of safety trials. Synergistic use of both computational and experimental approach to delineate molecule(s) of interest and to validate them in cell lines and animal models can expedite subsequent efficacy trials in humans [11]. In this paper, we try to review several potential repositioned therapeutics that have emerged from imprints in different countries. A range of already in use drugs have been shown to bind to important targets of SARS-CoV-2. These repurposed medications could possibly be used in a cocktail therapy subject to validation of drug interaction on a case-to-case basis. The purpose of this review is to compile the knowledge on the therapeutic potential of the reported molecules. We made a modest attempt to aid scientific community to design newer molecules using the reported ones as HITS and to formulate novel drug combinations to achieve enhanced outcomes. Moreover, this review also gives an insight into the drug targets within SARS-CoV-2.

\section{Proteins encoded by SARS-CoV-2 genome as potential therapeutic targets}

SARS-CoV-2 contains a single-stranded positive-sense RNA (+ ssRNA) of 29,903 nucleotides in length with 5'-cap and 3'-polyA tail. Typically coronavirus genome transcribes into $10 \mathrm{ORFs}$ ( 1 large genomic and at least 9 smaller subgenomic) of which the first ORF (ORF $1 \mathrm{a} / \mathrm{b}$ ) encodes for the key polyproteins pp1a and pp $1 \mathrm{ab}$ and covers nearly $60 \%$ of the entire genome. Other ORFs present in the downstream one-third region of the genome encode for four structural proteins along with special accessory proteins. These accessory proteins differ in different coronaviruses, with SARSCoV-2 containing 6 of them [12, 13]. Further, viral 3 chymotrypsin-like protease (3CLpro) or main protease (Mpro) with papain-like protease (PLpro), process these polyproteins into 16 nonstructural proteins: nsp1-16. These nonstructural proteins perform all the vital functions in viral replication and infection and hence, many among them are important drug targets [13, 14]. 
Nonstructural proteins like Nsp1 induce host mRNA degradation and strongly inhibit host protein synthesis. Additionally, it is reported to block the host's innate immune response, and hence plays an important role in the infection process $[15,16]$. Nsp3 is a multi-domain protein with at least 8 conserved domains throughout the family Coronaviridae [17]. It is the largest protein and performs many functions to support the survival of the virus by interfering with the host's antiviral response. In the early phase of infection, its binding to nucleocapsid protein is essential to establish infection and genome replication [18, 19]. The papain-like protease (PLpro), a subdomain of Nsp3, is responsible for cleaving Nsp1, 2, and 3 from the polyprotein [20]. Moreover, PLpro now is also known to demonstrate de-ubiquitinating and de-ISGylating (removal of ubiquitin-like protein ISG15) activities, justifying the role of Nsp3 in suppressing host's immune response [21]. Nsp3b, also known as 'X-domain' (Macro-domain 1) has a predicted function of ADP-ribose1"-phosphatases (ADRPs). Thus, various domains of Nsp3 in themselves are attractive targets for novel therapeutics $[22,23]$. Along with Nsp4, Nsp3 is also reported to play an important function in the rearrangement of host-derived membranes [24]. Nsp5, also known as 3CLpro, is autocleaved from polyprotein, and it then further cleaves downstream to ensure maturation of Nsp4-Nsp16 [25]. 3CLpro is highly conserved in SARS-CoV-2 and its function in processing key replicative proteins makes it an attractive anti SARS-CoV-2 target [26]. Nsp6 of SARS-CoV-2 generates auto-phagosomes. It is also reported to induce the formation of double-membrane vesicles (DMVs) along with Nsp3 and 4 [27, 28]. A complex of Nsp7-Nsp8 functions by enhancing the activity of RdRp and helps it bind to its substrate, i.e., RNA [29]. Nsp8 functions as a second RdRp and is involved in the synthesis of a primer, an oligonucleotide of fewer than 6 residues required by the primer-dependent main RdRp (Nsp12) [30]. Nsp9 in SARS-CoV is present as a dimer and binds RNA. It is known to mediate replication and virulence [31, 32]. Two critical proteins in a complex, nsp10/16, modify the viral genomic RNA to make it appear more like the host cell RNA and allow the virus to hide from the cells. Designing drugs to inhibit nsp10/nsp16 interaction would make it easier for the cells to detect the viral genome and clear it faster within the cell $[33,34]$. Nsp12 or RNAdependent RNA polymerase ( $\mathrm{RdRp}$ ) remains conserved in coronaviruses and synthesises the RNA strand in a primerdependent fashion [30, 35], making it a very good target for novel therapeutics and some of the currently approved drugs such as remdesivir are directed against it. Helicase or Nsp13 works in $5^{\prime}-3^{\prime}$ direction to separate double-stranded DNA and RNA. It is highly conserved in coronavirus and helps in its replication [36], making it a suitable potential target. Earlier recognised as an $\mathrm{Mg}^{+2}$-dependent $3^{\prime}-5^{\prime}$ exoribonuclease, which played a crucial role in proof-reading and repair, Nsp14 is now also found to function as N7 Methyltransferase (N7-MTase) to methylate the RNA cap at the N7 position. Interestingly, its exonuclease activity also removes the incorporated nucleoside analogues from RNA and, thus, poses a challenge to Nucleoside analogue (NA) drugs [34, 37-39]. This makes Nsp14 a suitable target that should be simultaneously targeted, along with NAs targeting RdRp. While Nsp15 functions in viral replication and transcription as a $\mathrm{Mn}^{+2}$-dependent nidoviral uridylatespecific endoribonuclease (NendoU), present in Nidovirales order to which the family Coronaviridae belongs [40]. Nsp16 is a $2^{\prime}-O$-methyltransferase ( $2^{\prime}-O$-MTase) and in complex with Nsp10 helps to methylate cap-0 to form cap- 1 structure $[33,41]$. Interestingly, it was reported that NendoU fails to cleave RNAs with 2-O-ribose methyl groups, which possibly explains the close association of Nsp15 and Nsp16 [42].

Like all other beta-coronaviruses, SARS-CoV-2 genome encodes four structural proteins, i.e., Spike (S), nucleocapsid $(\mathrm{N})$, membrane $(\mathrm{M})$, and envelope $(\mathrm{E})$, which play a vital role in its attachment to host cell, replication, and assembly of the mature virus [43]. With around 75\% homology to SARS-CoV, the spike protein of SARS-CoV-2 extends till an ecto-domain fragment via a trans-membrane moiety starting from a short cytoplasmic segment $[44,45]$. S protein is present as a homo-trimer, with each monomer consisting of S1 and S2 subunit [45]. S1 helps in the attachment to host cells while the $\mathrm{S} 2$ subunit mediates membrane fusion during infection. S protein is required to be cleaved by host cell protease TMPRSS2 to facilitate the internalisation of the virus [46]. S1 subunit hosts a receptor-binding domain (RBD) that binds the human ACE2 (Angiotensin-Converting Enzyme 2) [46] with a better affinity than that in SARS-CoV [45]. A cascade of events then leads to disruption of the $\mathrm{S} 1$ subunit and formation of a more stable S2 subunit, thus facilitating the fusion of viral and cell membranes [46, 47]. Hence, spike protein determines the host range and primarily interacts with the host receptor to establish infection, making it an attractive target for therapeutics [43]. Envelope proteins are integral structural proteins that form viroporins and mediate pathogenesis [48]. While E protein (form E channel) plays an important role in virus assembly and release [49], the $\mathrm{M}$ or Membrane protein helps shape the virions and in the interaction of viral envelope proteins ( $\mathrm{S}$ and $\mathrm{E}$ ) with the nucleocapsid protein, thus playing a central role in mediating viral assembly [50]. Disrupting its interaction with either $\mathrm{N}$ or $\mathrm{E}$ or $\mathrm{S}$ protein can stall the assembly process. Nucleocapsid or N protein binds the viral RNA and helps in its encapsidation. Upon fusion of viral and host membranes, $\mathrm{N}$ protein interacts with cellular processes and helps to wind down the host cell replication and overall immune response $[43,51]$. This makes all the structural proteins important for directing novel therapeutics. 
Table 1 Structural and nonstructural proteins of coronavirus and their functions

\begin{tabular}{lll}
\hline S no & PROTEIN/(references) & Function \\
\hline 1 & Spike Protein [43-47] & $\begin{array}{c}\text { Attach to host cell (receptor); membrane fusion } \\
\text { during infection }\end{array}$
\end{tabular}

2 Envelope Protein [48, 49]

3 Membrane Protein [50]

4

Nucleocapsid Protein $[43,51]$ Binds viral RNA; helps in encapsidation; postfusion processing to enhance survival

$5 \quad$ Nsp1 $[15,16]$

$6 \quad$ Nsp2 [20]

$7 \quad$ Nsp3 [17-23]

$8 \quad$ Nsp4 [24]

$10 \quad$ Nsp6 [27, 28]

$11 \quad$ Nsp7 [29]

12 Nsp8 [29, 30]

$13 \quad$ Nsp9 [31, 32]

14 Nsp10 [33, 34]

$15 \quad$ Nsp11

16 Nsp12 [30, 35]

$17 \quad$ Nsp13 [36]

18 Nsp14 [34, 37-39]

$19 \quad$ Nsp15 $[40,42]$

20 Nsp16 [33, 41, 42] orins central role in the assembly immune response, degrades host mRNA, and inhibits host protein synthesis making virions more contagious

It has multiple subdomains: an acidic domain tions as papain-like protease and also acts to suppress the interferon response the formation of double-membrane vesicles (DMVs)

Chymotrypsin-like protease (3CLpro) which is highly conserved in coronaviruses. It cleaves Nsp16 of double-membrane vesicles (DMVs)

Nsp7-Nsp8 enhances enzyme activity and thus used by Nsp12 RdRp

Unclear ruses

Helicase; works in 5'-3' direction $\mathrm{Mn}^{+2}$ dependent nidoviral uridylate-specific endoribonuclease (NendoU)

2'-O-Methyltransferase (2'-O-MTase) [Nsp10/
Helps in viral assembly and release; form virop-

Shape the virions; helps in mediating interactions of other structural proteins and therefore plays a

Critical virulence factor: Suppresses host innate

Unclear; may function in the infection process by (Nsp3a); Nsp3b, also known as 'X-domain', function as ADP-ribose-1"-phosphatases (ADRPs); $\mathrm{Nsp3c}$ is a SARS unique domain; Nsp3d func-

Along with Nsp3 plays an important role in rearrangement of host-derived membranes; induces downstream and ensures maturation of Nsp4-

Generates autophagosome; induces the formation processivity of RdRp and helps it bind to RNA

Primer-independent RdRp; synthesise primers to be Nsp7-Nsp8 complex [Refer Nsp7]

Binds RNA; mediates replication and virulence

Promotes binding of Nsp16 to both S-adenosyl-Lmethionine (SAM) cofactor and RNA substrate

Primer-dependent RdRp; conserved in coronavi-

N7 Methyltransferase (N7-MTase) [generate cap-0 structure]; $\mathrm{Mg}^{+2}$-dependent 3'-5' exoribonuclease Nsp16 methylates cap-0 to form cap-1structure]; help virus escape host immune response

Unavailable

6W9C: PLpro
PDB ID (SARS-CoV-2)

6VXX: S protein (closed state)

6VYB: $S$ protein (open state)

6VW1: RBD-ACE2 complex

6LXT, 6M1V: Post fusion core of S2 subunit

Unavailable

Unavailable

6M3M: N-terminal Domain (NTD) of N protein 6WJI: C-terminal Domain (CTD) of $\mathrm{N}$ protein

Unavailable

6WEY: 'X domain' of Nsp3

6W02: ADRP complex with ADP ribose

6W6Y: ADRP complex with AMP

6WX4: PLpro in complex with peptide inhibitor

VIR251

6WUU: PLpro in complex with peptide inhibitor VIR250

Unavailable

6M2Q: 3CLpro apo structure

6LU7: Main protease in complex with an inhibitor N3

Unavailable

6WIQ, 6WQD: Complex of Nsp7 and C-terminal domain (CTD) of Nsp8

6W4B: Nsp9

6W75, 6W4H, 6WKS: Nsp10-Nsp16 Complex 7C2J: Nsp16-Nsp10 complexed with SAM

Unavailable

7BW4: RdRp

6M71, 7BV1: nsp12(RdRp)-nsp7-nsp8 complex 7BV2: Nsp12-Nsp7-Nsp8 complexed with templateprimer RNA and remdesivir triphosphate

6ZSL: Helicase (nsp13)

6XEZ: Helicase bound to replication-transcription complex

Unavailable

6VWW: Nsp15

6W01: Nsp15 complexed with a citrate

Nsp10-Nsp16 Complex [Refer Nsp10] 
Table 1 provides a list of structural and nonstructural proteins of coronaviruses with their functions and Protein Data Bank (PDB) IDs. However, some proteins do not have their structures deduced yet, and homology models can be generated and used for in silico screening.

\section{Repurposed therapeutics}

SARS-CoV-2 gets transmitted exceedingly fast among the population and none on the planet has immunity to this virus as no one's immune system had seen it before 2019. The infection spread to an unaware, unprepared population world over resulting in such an unprecedentedly large number of infected patients and fatalities despite comprehensive efforts by WHO and governments of all the countries, causing wide-scale lockdowns of cities and states. Countries banned not only international and domestic flights but also trains and road transport, bringing life to stand still for months altogether. This situation mandates time bound and immediate need for remedies. There have been occurrences in the past where a drug, either serendipitously or by retrospective studies, has been granted approval for indications that are beyond the scope for which it was originally intended. One of the very first examples, Zidovudine, a drug originally indicated for cancer, went on to become the first FDA-approved antiHIV drug. Another example is of a drug which was under trial to treat hypertension when it was retrospectively found to cure erectile dysfunction-Sildenafil [52]. It then went on to hold major market share in such a category of drugs. While this approach could save pharmaceutical companies in capitals, the odds of accomplishing a cure are of more interest (Extensively reviewed by Pushpakom and coworkers [11]). Multiple trials are being done across the world to test several therapeutic options for COVID-19, mostly focusing on drug repurposing to achieve a fast resolution. These are enlisted in drugbank's COVID-19 information dashboard (https://www.drugbank.ca/covid-19) and Milken Institute's COVID-19 treatment and vaccine tracker (https ://covid-19tracker.milkeninstitute.org/). In this review, we compiled promising candidates for drug repositioning and the results of their clinical trials as of now. Table 2 provides a compiled list of all the described repurposed therapeutics in various stages of clinical trials.

\section{Remdesivir}

Remdesivir is a prodrug of a nucleotide analogue and was initially designed against Ebola by Gilead Sciences, Inc. It works by inhibiting viral RNA polymerases after being metabolised to an analogue of adenosine triphosphate and has shown in vitro therapeutic efficacy against SARS and MERS coronaviruses and also against SARS-CoV-2 with Nsp3b [have a predicted function of ADP-ribose-1"phosphatases (ADRPs)], RdRp, E-channel (E protein), and type-II transmembrane serine protease (TMPRSS2) enzymes as potential binding targets [53-55]. With several studies in moderate and severe COVID-19 patients still on, in one of the trials in a small cohort, Grein and co-workers suggest that remdesivir may have clinical benefits in severe COVID-19 patients with improvement in oxygen-support status. Though, the majority of them also experienced common side effects like increased hepatic enzymes, diarrhoea, renal impairment, and hypertension. However, with a small sample size, it was also reported that improvement was comparatively less frequent in cases with invasive ventilation than those on non-invasive support and in patients above 70 years as compared to those younger than 50 years [56]. Intravenous remdesivir was administered to the first confirmed COVID-19 patient in the United States, and improved clinical symptoms were observed [57].

However, findings of another randomised, double-blind, placebo-controlled clinical trial in Hubei, China, found no significant benefits of treatment of severe COVID-19 with remdesivir over normal supportive care. Wang and co-workers reported that patients receiving remdesivir showed faster clinical improvement, but this was statistically insignificant [58]. Another preliminary report from a randomised, controlled trial [Adaptive COVID-19 Treatment Trial 1 (ACTT-1)] comprising 1063 patients suggests that treatment with remdesivir lead to 31 percent faster recovery time, the median of which was 11 days as compared to 15 days of the group, that received placebo [59]. These results prompted successive trials ACTT-2 (Remdesivir plus Baricitinib against Remdesivir; NCT04401579) and ACTT-3 (Remdesivir plus Interferon Beta-1a against Remdesivir; NCT04492475) to formulate better treatment regimen (https ://clinicaltrials.gov/). Remdesivir is now cleared for emergency use by the US FDA (Food and Drug Administration) [60].

\section{Lopinavir and ritonavir}

Lopinavir is an antiviral used to treat Human Immunodeficiency Virus (HIV) type 1 infection. It inhibits HIV protease, and when used along with Ritonavir, the plasma halflife of lopinavir increases. It has shown inhibitory activity against SARS-CoV in vitro [61].

In a randomised, controlled, open-label trial in 199 patients, $\mathrm{Cao}$ and co-workers observed that there was no significant improvement in clinical signs or mortality upon treatment in 99 patients of the lopinavir-ritonavir group. The authors found that though the treatment reduced the patient's stay in intensive care units (ICU), there were significant gastrointestinal adverse events in this group against those which did not [62]. These findings were substantiated 


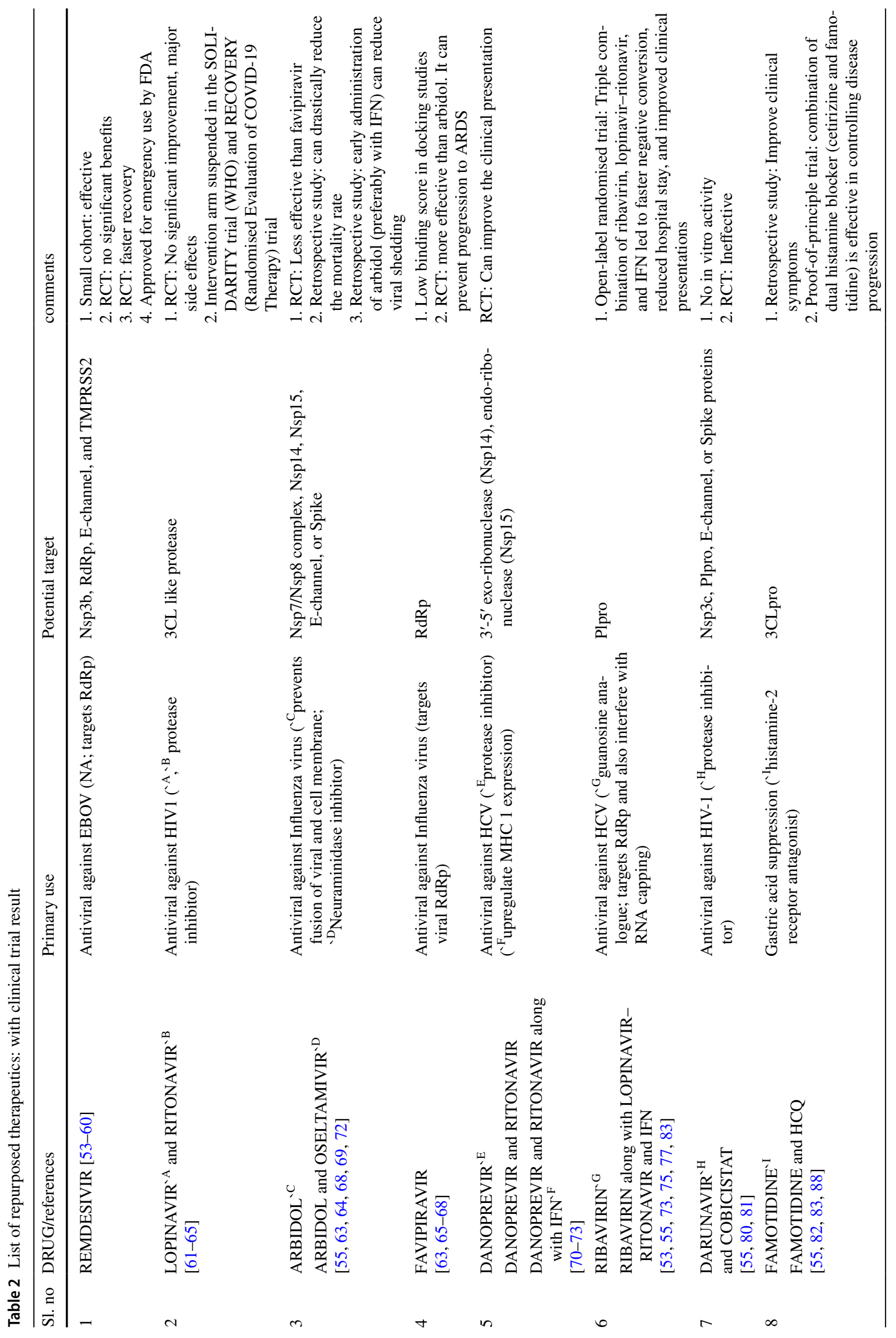




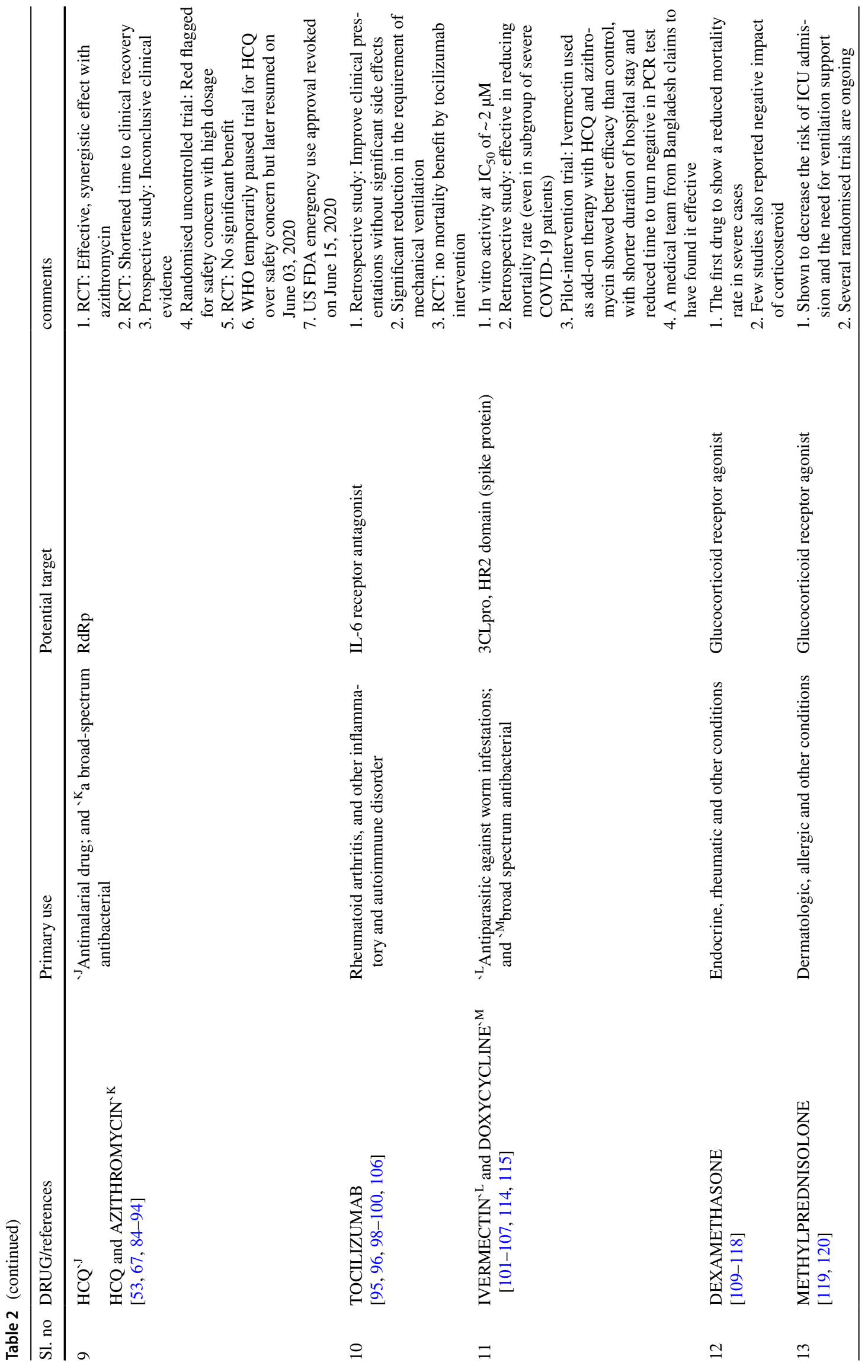


by other randomised controlled trial and docking studies [63]. Lopinavir-ritonavir SOLIDARITY trial (WHO) and RECOVERY (Randomised Evaluation of COVID-19 Therapy) trial were suspended after failing to find any clinical benefits $[64,65]$.

\section{Arbidol/favipiravir/arbidol and oseltamivir}

Arbidol, a broad-spectrum antiviral drug used against influenza and other respiratory viral infection in Russia and China, works by inhibiting the fusion of the virus' lipid membrane with the host cells $[55,66]$. Favipiravir, an antiviral used primarily against influenza infection, works by targeting the influenza viral RNA-dependent RNA polymerase (RdRp) [67]. It has a broad spectrum activity owing to the conserved nature of the catalytic domain of RdRp among various types of RNA viruses [68]. Both Influenza and SARS-CoV-2, being the RNA viruses, require RdRp for genome replication and have similar clinical presentations. Efficacy of both arbidol and favipiravir is now being investigated for the treatment of COVID-19. Docking studies predicted arbidol to potentially bind to Nsp7-Nsp8 complex, Nsp14 (exoribonuclease), Nsp15 (endoribonuclease), E protein, and/or Spike protein [55]; and favipiravir to bind RdRp in SARS-CoV-2 [69]. However, Chen and co-workers, in a prospective, multicenter, open-labeled, randomised superiority trial, found favipiravir to have a superior clinical recovery rate as compared to arbidol in moderate patients with COVID-19 infection [70] and indicated its use to prevent progression of disease into Acute Respiratory Distress Syndrome.

Another RCT supported this by concluding that treatment with arbidol may not improve clinical outcomes in mild/ moderate COVID-19 patients [63]. However, in a retrospective study of 504 patients with confirmed COVID-19 infection in China, Liu and co-workers came to a different conclusion. On carefully studying data of these patients, the authors found that arbidol treatment led to slightly higher $\mathrm{SpO} 2$ levels and showed faster lesion absorption. This preprint report suggests that arbidol either alone or in combination with oseltamivir can drastically reduce mortality rate [71]. Further, in a retrospective study in 238 hospitalised COVID-19 patients in China, a prolonged viral shedding was correlated with delay in arbidol intervention (more than 7 days after illness onset) compared to those patients which received arbidol within 7 days of illness onset. Also the viral shedding was reduced in patient receiving combination of arbidol and interferon, compared to those receiving arbidol alone [72]. Oseltamivir as monotherapy or in combination with the other drugs is currently under multiple trials (NCT04303299, NCT04338698, NCT04457609, NCT04261270) to ascertain its efficacy in the treatment of the COVID-19 patients. 


\section{Danoprevir/danoprevir and ritonavir/danoprevir and ritonavir along with interferon}

Approved and marketed in China since 2018, Danoprevir is an antiviral used to treat chronic hepatitis $\mathrm{C}$ patients by inhibiting $\mathrm{HCV}$ protease (NS3/4A) and is demonstrated to be safe and well tolerated in HCV patients. It is often boosted with ritonavir (an HIV protease inhibitor in itself at high dosage), to enhance its plasma concentration [73, 74]. Danoprevir is predicted to bind to $3^{\prime}-5^{\prime}$ exoribonuclease (Nsp14), endoribonuclease (Nsp15) of SARS-CoV-2 [75].

A study suggests that in moderate COVID-19 patients, 4-12 days treatment of danoprevir/ritonavir in the presence or absence of interferon nebulisation can suppress viral replication and improve clinical conditions. In a trial with 11 patients, Chen and co-workers found that patients with hypertension or those who did not respond to treatment with lopinavir/ritonavir with or without worsening of symptoms were showing negative PCR test after treatment with danoprevir/ritonavir at a median of 2 days, ranging from 1 to 8 days with reduced ground-glass opacity [76]. This study also stresses the importance of containing the disease from progressing from a moderate to severe level. However, randomised controlled trials with a larger cohort are required to further substantiate the usefulness of danoprevir in the treatment of SARS-CoV-2 infection.

\section{Ribavirin/ribavirin and interferon}

Ribavirin is a guanosine analogue that, through multiple mechanisms, interferes with the replication of RNA and DNA viruses. Other than targeting polymerases, it is also found to interfere with RNA capping that is dependent on natural guanosine, by inhibiting the latter's generation, and hence destabilises viral RNA. Viral replication in the presence of ribavirin occurs with reduced fidelity inducing random mutations, further reducing its viability [77, 78]. In safety trials of ribavirin for chronic HCV infection, the adverse effects were well established and were found to be well tolerated [79]. However, it is contraindicated during pregnancy, owing to its teratogenic properties [80].

Ribavirin was used during SARS infection in 2003, but findings remained unclear due to the deleterious effects of previous treatment and demanded more placebo-controlled trials. Likewise, during the MERS outbreak, the benefits of administering ribavirin were not sufficient to outplay its toxicity. With promising in vitro results, then against SARS$\mathrm{CoV}$ and MERS-CoV and now against SARS-CoV-2, ribavirin is currently under clinical trial (NCT04356677) in combination with standard care therapy in Canada to check its efficacy against SARS-CoV-2 in humans [53, 61, 80, 81]. Chinese guidelines for the treatment of COVID-19 mention ribavirin in combination with IFN alpha as one of the therapeutic options [82]. Docking studies further suggest PLpro of SARS-CoV-2 as a potential target for ribavirin with low binding energy [55] in addition to RdRp. In an openlabel randomised trial in 127 patient, a triple combination of ribavirin, interferon beta- $1 \mathrm{~b}$ and lopinavir-ritonavir when compared to lopinavir-ritonavir, led to a significantly shorter median time to convert nasopharyngeal swab negative for viral RNA, reduced duration of hospital stay, and a better clinical improvement with only mild side effects [83]. Data from other ongoing trials (NCT04392427, NCT04460443) would prove helpful in further establishing if it provides more benefits on early administration upon presentation with pneumonia than when the situation worsens.

\section{Darunavir and cobicistat}

Darunavir is an HIV-1 protease inhibitor which is used in combination with cobicistat as a pharmaco-enhancer. Docking results found it to have an affinity to SARS-CoV-2 Nsp3c, PLpro, E-channel, or Spike proteins, but the affinity for the main protease (3CL protease) was of most interest [55]. Closer visualisation showed that darunavir had very few interactions with the important residue of 3CL protease and was found to have no in vitro activity against SARSCoV-2 [84, 85]. However, it still underwent a clinical trial on 30 COVID-19-positive patients at Shanghai Public Health Clinical Centre, and results showed that it was indeed ineffective [85]. Another clinical trial NCT04304053, dropped darunavir owing to in vitro data and other findings.

\section{Famotidine/famotidine and hydroxychloroquine (HCQ)}

Famotidine is a histamine-2 receptor antagonist and is commonly used for gastric acid suppression. It has shown in vitro antiviral properties against HIV replication [86]. Docking studies suggest that famotidine is likely to inhibit 3CLpro [55], which is essential for proteolytic processing of the SARS-CoV-2 polypeptide, and hence for viral replication. In a retrospective cohort study with large sample size, it was found that the use of famotidine in COVID19 patients who were not in an intensive care setting, initially led to a twofold reduction in clinical deterioration. These patients were at reduced risk for intubation or death [87]. Further, a combination of dual histamine blocker (H1 antagonist Cetirizine, and $\mathrm{H} 2$ antagonist Famotidine) was used in a proof-of-principle, non-randomised, un-controlled trials and was found to be effective in a good prognosis and reduced ventilator support [88]. A randomised clinical trial (NCT04370262) is now being carried out to assess the efficacy of famotidine in combination with HCQ for the treatment of COVID-19. 


\section{Hydroxychloroquine/HCQ and azithromycin}

HCQ is an antimalarial drug first approved by the FDA in 1955. It is a derivative of chloroquine (CQ) but has less toxicity. Apart from its use for the treatment of uncomplicated malaria, it is also prescribed for rheumatoid arthritis (RA) and systemic lupus erythematosus [89]. In the current crisis, it remained the most controversial molecule, and various studies reported it to be effective, while others found it ineffective and still others reported adverse effects of HCQ in COVID-19-affected individuals. Studies demonstrated that HCQ and CQ have a potent in vitro activity against SARS-CoV-2 [53], which is attributed to an increased endosomal $\mathrm{pH}$, and its anti-inflammatory and immunomodulating effects [90]. On March 28, 2020, the FDA gave emergency use approval for the use of chloroquine phosphate and hydroxychloroquine sulphate to treat adult COVID-19 patients but later revoked it on June 15, 2020 considering its "known and potential risk" [91].

Studies in favour: An open-label, non-randomised trial was conducted in 36 patients in which 26 patients received hydroxychloroquine. 6 patients in the hydroxychloroquine group also received azithromycin. Despite a small sample size, Gautret and co-workers found that after 6 days of treatment, $100 \%$ of patients who received azithromycin and hydroxychloroquine together were negative for SARS-CoV-2; against $57.1 \%$ of those who received only hydroxychloroquine and $12.5 \%$ in the control group. Authors thus reported hydroxychloroquine as a potent drug to clear COVID-19 and found even better results when used synergistically with azithromycin [92]. In another randomised clinical trial in 62 COVID-19 patients, Chen and co-workers reported that 31 patients assigned to receive hydroxychloroquine(HCQ) showed shortened time to clinical recovery (TTCR) and improved absorption of pneumonia. Significantly reduced duration of high body temperature, recovery time, and cough remission time were reported in the HCQ group [93].

Studies against: This was contradicted when Molina and co-workers did not find any strong clinical evidence when in a prospective study, 11 severe COVID-19 patients with significant comorbidities were administered HCQ $(600 \mathrm{mg} / \mathrm{d}$ for 10 days) and azithromycin (500 mg on day 1 and $250 \mathrm{mg}$ on days 2-5) in the same dosage as used by Gautret and co-workers $[92,94]$. Another uncontrolled double-blinded, randomised trial in 81 patients conducted to address different treatment dosage of chloroquine in severe COVID-19 patients red-flagged the use of high dosage (12 $\mathrm{g}$ of CQ in total, for 10 days) due to potential safety hazard [95]. No significant benefit of HCQ treatment was found by Tang and co-workers in an open-label, randomised, controlled trial with 75 patients in the HCQ group. In mild to moderate COVID-19 patients, the negative conversion probability in both the groups remains approximately similar. However, there were more adverse effects in the HCQ recipient group [96]. Even for COVID-19 patients with hypoxic pneumonia, there was no reduction in ICU admission or death after 7 days of hospital admission when treated with HCQ [97]. Thus, the efficacy of HCQ with or without azithromycin remains questionable and demands more randomised controlled trials. On May 25, 2020, WHO temporarily paused the trial of HCQ within its solidarity trial, owing to safety concerns [98] but later resumed it on the recommendation of the data safety and monitoring committee on June 03 , 2020, only to again discontinue it on July 04, 2020 [64, 99].

\section{Tocilizumab}

Cytokine storm mediated by IL-6 plays a significant role in COVID-19 patients with severe symptoms (discussed above). Tocilizumab, an anti-human IL-6 receptor monoclonal antibody, works by binding to soluble and membranebound IL-6 receptors (sIL-6R and mIL-6R, respectively) preventing IL- 6 binding and, thus, inhibits signal transduction pathway. It was found to be well tolerated and is currently approved for the treatment of severe rheumatoid arthritis and other inflammatory and autoimmune conditions [100, 101].

With randomised trials (NCT04310228, NCT04317092, NCT04339712, NCT04330638, NCT02735707, NCT04372186 https://clinicaltrials.gov) still underway, there have been several retrospective studies. In one such study, it was reported that tocilizumab treatment in 21 severe and critical COVID-19 patients in China resulted in improved clinical presentations with no significant adverse effects. This study suggested that early treatment could also prevent deterioration of symptoms [102]. A different retrospective study at the Italian center found that bacterial superinfection in ICU settings could complicate treatment with tocilizumab [103]. 30 COVID-19 patients in France with severe and rapidly deteriorating pneumonia were treated with tocilizumab. When compared with the control group, Roumier and co-workers reported a significant reduction in mechanical ventilation requirements and reduced risk of ICU admission [104]. Similar improved survival was reported from a retrospective case-control study at a medical center in New York [105]. Further, reports from first randomised, placebo-controlled trial (COVACTA trial) of tocilizumab found no benefits in the death rates in the intervention arm. This study did not meet its primary endpoint (clinical status on a 7-category ordinal scale: 1 for discharge/ready to be discharged; to 7 for death) and the clinical presentations were not improved significantly as compared to control. However, reduced duration of hospital stay (median 8 days shorter than placebo) and ICU stay (median 5.8 days shorter than placebo) 
were demonstrated in patients treated with tocilizumab [106]. These results contradict the earlier reports from various retrospective trials and indicate no effect of tocilizumab in managing mortality in COVID-19 patients. Results from further trials are awaited to support or refute the existing evidences.

\section{Ivermectin and doxycycline}

Ivermectin is an FDA-approved broad-spectrum antiparasitic medication used against worm infestations. It has shown to inhibit several viruses, including HIV-1, Dengue, among others in vitro $[107,108]$. This broad-spectrum activity of ivermectin is attributed to targeting of host importin (IMPa/ß1) transport protein, which is used by many viruses during infection [109].

Caly and co-workers recently reported in vitro activity of ivermectin against SARS-CoV-2 with $\sim 5000$-fold reduction in the viral RNA load in $48 \mathrm{~h}$ at $\mathrm{IC}_{50}$ of $\sim 2 \mu \mathrm{M}$ [110]. However, it remains to be seen if such high plasma concentration could be safely attained, provided that it targets the host protein [111]. A bioinformatic study suggests that ivermectin could potentially bind to $3 \mathrm{CL}$ protease and the HR2 domain (spike protein) of SARS-CoV-2 synergistically [112]. Thus, a randomised control trial could shed more light on the efficacy of ivermectin in treating COVID-19, and multiple such studies are currently underway (https://clinicaltrials.gov/). However, Chaccour and coworkers pointed out that concurrent use with boosted antivirals like lopinavir/ritonavir and darunavir/ cobicistat could increase systemic concentration (leading to neurotoxicity) of ivermectin [113]. A multicenter, retrospective cohort study at four hospitals in South Florida showed ivermectin to have significant effect in lowering mortality rate even in severe COVID-19 cases. However, no difference in duration of hospital stay or rate of extubation was observed in intervention and control arms [114]. In a pilot interventional trial in mild to moderate patients, a single dosage of ivermectin used as an add-on therapy over HCQ and azithromycin (ivermectin group) showed better efficacy when compared to synthetic controls (patients already treated and later used as an external control) receiving hydroxychloroquine and azithromycin alone [115]. Meanwhile, a medical team from Bangladesh claimed to have treated all 60 patients with a combination of ivermectin and doxycycline within 4 days without any adverse effect [116]. Retrospective and pilot trials are often bound by puzzling factors, albeit unmeasured at times. Larger placebo-controlled randomised trials are required to derive better evidence on effectiveness of ivermectin. However, such placebo-controlled trials tend to be unethical at times of pandemic.

\section{Dexamethasone}

Corticosteroids have been reported in several retrospective studies to prevent the worsening of symptoms and reduce the risk of intubation [117-119]. Treatment with corticosteroid was associated with faster alleviation of high body temperature and improvement of $\mathrm{SpO} 2$ when compared with the group which did not receive them [120]. However, some other studies found increased mortality risks on the administration of corticosteroids with more cases of multiple organ dysfunctions [121, 122]. As described earlier, the deleterious effect of high levels of pro-inflammatory cytokines leads to extensive mortality in severe cases. Corticosteroid is an immunosuppressive drug that winds down the immune response and also helps to reduce inflammation. This antiinflammatory response could thus prevent further alveolar damage [123]. However, the use of steroids was not advised by WHO for treatment of COVID-19 cases due to adverse effects and delayed rate of viral clearance as experienced in previous outbreaks during SARS-CoV, MERS-CoV, and H1N1 epidemics [124].

One such inexpensive steroid, dexamethasone is the first drug to have shown to reduce mortality in severe COVID19 cases. In one of the arms of RECOVERY (Randomised Evaluation of COVID-19 Therapy) trial in the UK, dexamethasone was found to prevent one-third of the deaths of patients requiring mechanical ventilation. 2104 enrolled patients were administered a dose of $6 \mathrm{mg}$ per day of the drug for 10 days while 4321 patients in the control group received only the standard care. It was preliminarily reported that dexamethasone does improve the chances of survivability in severe COVID-19 cases. The patients on oxygen therapy also reported 20 percent reduced mortality; however, there were no effects on less severe cases (those not requiring oxygen support). Following this, it was immediately authorised by the UK government for use in patients requiring oxygen support, including those who need mechanical ventilation [125-127].

Another FDA-approved glucocorticoid methylprednisolone has shown to benefit moderate to severe COVID19 patients in a multicentric, partially randomised trial. This study reflects on the benefits of a short term course of methylprednisolone to decrease the risk of admission to ICU or need for ventilation support and posed no major side effect. However, hyperglycemia was frequently observed [128]. Another multicentre observational study concluded that early treatment of severe cases with methylprednisolone could prevent disease progression [129]. Results from several ongoing randomised trials (NCT04263402, NCT04345445, NCT04329650) could shed more light on its efficacy in the treatment of COVID-19 cases. In a meta-analysis by the 'WHO Rapid Evidence Appraisal for COVID-19 Therapies (REACT) Working Group', results 
from 7 randomised clinical trials covering 1703 critical COVID-19 patients (678 to corticosteroid against 1025 in control group) from 5 continents suggested lowered allcause-mortality after 28 days post randomisation. Overall $32 \%$ mortality was documented in corticosteroid intervention group against $40 \%$ in placebo. The analysis further recommended corticosteroid intervention along with standard care for critically ill COVID-19 patients, 'in the absence of compelling contraindications' [130].

\section{Convalescent plasma}

Convalescent plasma from recovered patient has been used historically to treat diseases in the events of lack of prophylactic or therapeutic interventions [131]. This mode of intervention is under trial for the treatment of COVID-19 patients. In a Cochrane review consisting a total of 5443 participants in 20 studies (16 non-controlled non-randomised studies of interventions (NRSIs), 3 controlled NRSIs, and 1 Randomised control trial), no certain evidence to substantiate the efficacy of convalescent plasma in reducing mortality, or improving clinical symptoms, or prolonging time-todeath was found [132]. Similarly, a randomised control trial in Netherlands did not conclude improvement in mortality and severity in the intervention arm. This study was however prematurely halted on recommendation of data safety monitoring board [133]. A more recent randomised control trial was reported from India, wherein 464 participants underwent randomisation (235 in intervention arm against 239 in control arm) at 39 trial sites. Authors found no significant difference in mortality or disease progression among moderate COVID-19 patients. They, however, reported improved resolution of indications (like fatigue and shortness of breath), and faster negative conversion of viral RNA in patients in the intervention arm but failed to demonstrate any anti-inflammatory property [134]. Undergoing clinical studies (clinicaltrials.gov: NCT04333251; NCT04344535; NCT04345523; NCT04332835; NCT04342182; NCT04345991; NCT04345289; NCT04346446) on convalescent plasma therapy could add to existing knowledge when completed.

Furthermore, other immunotherapies using monoclonal antibodies, cytokines, interferon, and mesenchymal stem cell therapy are also under clinical trials in an effort to modulate immune response in COVID-19 patients (reviewed by Mansourabadi and coworkers [135]).

\section{Under-trial molecules}

With such a large number of infected patients, the pandemic warrants the immediate need for treatment. Multiple trials are being conducted across the world to test several therapeutic options in an effort to generate strong evidences and build a uniform treatment protocol. Table 3 enlists some interventions (investigational and approved) that are under trial against COVID-19 infection with their status from https ://clinicaltrials.gov/ and Chinese Clinical Trial Register (http://www.chictr.org.cn/); and primary usage information from drugbank (https://go.drugbank.com/).

\section{Molecules with favourable in vitro/docking results but not under clinical trial yet}

Table 4 enlists some drugs with favourable docking for SARS-CoV-2 targets but which are not currently under clinical trial. Anti-HIV drugs like nelfinavir have shown affinity for 3CLpro [136, 137]. Ganciclovir was found to potentially bind RdRp, exonuclease, and helicase [136]. In vitro activity against SARS-CoV-2 was also exhibited by miglustat which is expected to work at the host cell level. In the postinfection process, it targets folding and glycosylation of viral protein in the endoplasmic reticulum. Miglustat is an approved drug to treat some genetic disorders and the in vitro activity was observed at a safe and achievable plasma concentration level [138-140]. Targeting multiple proteins simultaneously could reduce the chances of developing resistance. Elbasvir has been shown to target key SARS-CoV-2 proteins like RdRp, PLpro, helicase, and also the viral spike protein [141]. N4-deoxycytidine, a ribonucleoside analogue with broad antiviral properties, and its prodrug EIDD-2801, have demonstrated in vitro efficacy in Vero cells against SARS-CoV-2 at an $\mathrm{IC}_{50}$ of $0.3 \mu \mathrm{M}$. It has been shown to be potent even against coronaviruses with resistance for other nucleoside analogue drugs like remdesivir [142].

\section{Conclusion}

This inimitable illness has affected the entire world's population, either directly or indirectly. With hundreds of thousands of deaths already recorded due to COVID-19, there are still no signs of infection trail slowing down. Many lowincome countries faced an added challenge of preventing deaths due to starvation and, hence, made efforts to open the economies. With aerosol as one of the primary modes of transmission among others [143], proper face masks, eye protection along with physical distancing measures could significantly reduce the chance of infection and prevent the healthcare system from being overwhelmed [144]. With no specific antivirals available, patients have primarily been provided symptomatic treatment, and the effort has been broadly aimed at containing the spread of infection.

Remdesivir, an antiviral that was initially being developed for Ebola infection, gained approval by the US FDA for 
Table 3 Antivirals under trial against COVID-19 infection with no results reported yet

\begin{tabular}{|c|c|c|c|c|}
\hline S1. no & Drug & Primary use & Trial id & Status \\
\hline 1 & CLEVUDINE & $\begin{array}{l}\text { Investigational for use in HBV } \\
\text { infection }\end{array}$ & NCT04347915 & RCT, recruiting, Phase 2 \\
\hline 2 & ASC-09 & $\begin{array}{l}\text { Investigational for use in HIV-1 } \\
\text { infection }\end{array}$ & NCT04261270 & RCT, Recruiting, Phase 3 \\
\hline 3 & GALIDESIVIR & $\begin{array}{l}\text { Investigational for use in Ebola } \\
\text { infection; broad-spectrum } \\
\text { antiviral }\end{array}$ & NCT03891420 & RCT, Recruiting, Phase 1 \\
\hline 4 & AZVUDINE & $\begin{array}{l}\text { Investigational for use in HIV-1 } \\
\text { infection }\end{array}$ & $\begin{array}{l}\text { 1. ChiCTR2000030487 } \\
\text { 2. ChiCTR2000030424 } \\
\text { 3. ChiCTR2000029853 }\end{array}$ & $\begin{array}{l}\text { 1.Non-randomised; recruitment } \\
\text { status unknown } \\
\text { 2.Non-randomised; recruitment } \\
\text { pending } \\
\text { 3.RCT, recruitment status unknown }\end{array}$ \\
\hline 5 & BALOXAVIR MARBOXIL & Antiviral against Influenza & ChiCTR2000029548 & RCT, Not yet recruiting \\
\hline 6 & EMTRICITABINE/ TENOFOVIR & Antiviral against $\mathrm{HIV}$ & ChiCTR2000029468 & Non-randomised; Not yet recruiting \\
\hline 7 & $\begin{array}{l}\text { METENKEFALIN + TRIDECAC- } \\
\text { TIDE }\end{array}$ & $\begin{array}{l}\text { Investigational for treatment of } \\
\text { multiple sclerosis }\end{array}$ & NCT04374032 & $\begin{array}{l}\text { Randomised, comparative; Recruit- } \\
\text { ing, Phase } 2\end{array}$ \\
\hline 8 & FINGOLIMOD & Treatment of multiple sclerosis & NCT04280588 & $\begin{array}{l}\text { Non-randomised; Recruiting, Phase } \\
2\end{array}$ \\
\hline 9 & IBUPROFEN & $\begin{array}{l}\text { NSAID used as an analgesic, anti- } \\
\text { inflammatory and antipyretic }\end{array}$ & $\begin{array}{l}\text { 1. NCT04382768 } \\
\text { 2. NCT04334629 }\end{array}$ & $\begin{array}{l}\text { 1. Compassionate Use Program; } \\
\text { Recruiting } \\
\text { 2. RCT, Recruiting, Phase } 4\end{array}$ \\
\hline 10 & EIDD-2801 & $\begin{array}{l}\text { Investigational for use in influenza, } \\
\text { MERS-CoV and SARS-CoV-2 } \\
\text { infection }\end{array}$ & $\begin{array}{l}\text { 1. NCT04405570 } \\
\text { 2. NCT04405739 }\end{array}$ & $\begin{array}{l}\text { 1. RCT, Recruiting, Phase } 2 \\
\text { 2. RCT, Recruiting, Phase } 2\end{array}$ \\
\hline 11 & ATAZANAVIR & Treatment of HIV infection & $\begin{array}{l}\text { 1. NCT04459286 } \\
\text { 2. NCT04468087 } \\
\text { 3. NCT04452565 }\end{array}$ & $\begin{array}{l}\text { 1. RCT, Not yet Recruiting, Phase } 2 \\
\text { 2. RCT, Not yet Recruiting, Phase } \\
\text { 2/3 } \\
\text { 3. RCT, Recruiting, Phase } 2 / 3\end{array}$ \\
\hline 12 & NAFAMOSTAT & $\begin{array}{l}\text { Used as anti-coagulant in patients } \\
\text { requiring renal replacement } \\
\text { therapy }\end{array}$ & $\begin{array}{l}\text { 1. NCT04352400 } \\
\text { 2. NCT04473053 }\end{array}$ & $\begin{array}{l}\text { 1. RCT, Not yet Recruiting, Phase } 2 \\
\text { 2. RCT, Recruiting, Phase } 2\end{array}$ \\
\hline 13 & OPAGANIB & $\begin{array}{l}\text { Investigational, Sphingosine } \\
\text { kinase-2 (SK2) selective inhibi- } \\
\text { tor }\end{array}$ & $\begin{array}{l}\text { 1. NCT04414618 } \\
\text { 2. NCT04467840 }\end{array}$ & $\begin{array}{l}\text { 1. RCT, Recruiting, Phase } 2 \\
\text { 2. RCT, Recruiting, Phase } 2\end{array}$ \\
\hline 14 & TELMISARTAN & Antihypertensive & $\begin{array}{l}\text { 1. NCT04360551 } \\
\text { 2. NCT04355936 } \\
\text { 3. NCT04359953 }\end{array}$ & $\begin{array}{l}\text { 1. RCT, Recruiting, Phase } 2 \\
\text { 2. RCT, Recruiting, Phase } 4 \\
\text { 3. RCT, Recruiting, Phase } 3\end{array}$ \\
\hline 15 & DIPYRIDAMOLE & Used as anticoagulant & $\begin{array}{l}\text { 1. NCT04424901 } \\
\text { 2. NCT04391179 } \\
\text { 3. NCT04410328 }\end{array}$ & $\begin{array}{l}\text { 1. RCT, Recruiting, Phase } 2 \\
\text { 2. RCT, Recruiting, Phase } 2 \\
\text { 3. RCT, Not yet Recruiting, Phase } 3\end{array}$ \\
\hline 16 & AT-001 & $\begin{array}{l}\text { Investigational, aldose reductase } \\
\text { inhibitor }\end{array}$ & NCT04365699 & $\begin{array}{l}\text { Non-randomised controlled trial, } \\
\text { Recruiting, Phase } 2\end{array}$ \\
\hline
\end{tabular}

[Status: ClinicalTrials.gov (https://clinicaltrials.gov/) and Chinese Clinical Trial Register (http://www.chictr.org.cn/); Primary usage information: Drugbank (https://go.drugbank.com/)]

NSAID Non-steroidal anti-inflammatory drug, $R C T$ randomised controlled trial

emergency use after showing impressive results in a US clinical trial $[59,60,145]$. In contrast, earlier few trials showed little or no clinical benefit. Treatment with Lopinavir/Ritonavir had many adverse gastrointestinal events with no clear benefits. However, it did reduce the patient's stay in the ICU [62]. This intervention regime has been dropped from both SOLIDARITY trial (WHO) and RECOVERY trial after failing to show clinical benefit $[64,65]$. Chen and co-workers reported that patients who did not respond to treatment with lopinavir/ritonavir reported negative PCR tests after treatment with danoprevir/ritonavir [76]. Approved for the treatment of influenza infection, both arbidol and favipiravir indicated clinical recovery. Favipiravir was also suggested to prevent the progression of the disease to ARDS, which is one of the primary reasons for death in severe cases [70, 71]. There is a 'cytokine storm' in the latter phase of the 
Table 4 Drugs with favourable results but not under clinical trial against COVID-19 infection

\begin{tabular}{llll}
\hline S1. no & DRUG/references & Primary use & Potential target \\
\hline 1 & VALGANCICLOVIR [55] & Treatment of cytomegalovirus infection & Plpro \\
2 & SAQUINAVIR [55] & Treatment of HIV infection & Helicase(Nsp13) \\
3 & NELFINAVIR [137] & Treatment of HIV-1 infection & 3CLpro \\
5 & GANCICLOVIR [136] & Treatment of cytomegalovirus infection & RdRp, 3'-5' exonuclease, Helicase \\
6 & MIGLUSTAT [138-140] & Treatment of Gaucher disease; and Niemann- & Folding and glycosylation of \\
& & Piral protein in Endoplasmic & Reticulum \\
7 & ELBASVIR [141] & Treatment of Hepatitis C virus infection & RdRp, PLpro, Helicase, S protein \\
8 & N4-HYDROXYCYTIDINE [142] & Experimental broad-spectrum antiviral; ribonu- & RdRp \\
\end{tabular}

disease, which may lead to ARDS. Tocilizumab, an IL-6 receptor inhibitor, was initially suggested to wind down this storm and prevent deterioration of symptoms [104, 105, 146]. However, tocilizumab failed to provide any mortality benefit when compared to control [106]. With increasing safety concerns, the role of HCQ largely remains unclear in tackling COVID-19 infection. The US FDA recently revoked the emergency use approval for HCQ over safety concerns [91]. Further, convalescent plasma therapy that initially looked promising failed to impart any significant benefit in reducing mortality or curtailing disease progression. It however, resulted in faster negative conversion and improved symptom resolution when compared to controls [134].

So far ivermectin and doxycycline appeared to be an effective therapeutic combination [116] supported by data from a retrospective study which found ivermectin to significantly lower mortality rate [114]. In a first result of its kind, steroid dexamethasone was reported from a RECOVERY (Randomised Evaluation of COVID-19 Therapy) trial in the UK to reduce mortality in severe COVID-19 cases [125, 126]. Being an RNA virus and under antiviral pressure, SARS-CoV-2 is prone to mutations. Combination therapy is thus desirable, which could address multiple targets of the virus and reduce the chance of developing drug resistance [76] that could potentially be used on a case-to-case basis subject to validation of drug interaction. Availability of a convenient animal model a "Syrian hamster" [147] may prove to be appropriate for studying the pathogenesis of SARS-CoV-2, and evaluating immunotherapies and antiviral drugs. It will overcome the shortcomings of the previously available animal models namely hACE2 transgenic mice and macaques (primate model) to a great extent [148].

There is a clear need to channel information from various trials to delineate a standard treatment protocol and guiding the future clinical trials. With hundreds of trial still in the pipeline and many already reporting conclusions, a compiled review serves as a quick source for reliable information. Till date, dexamethasone have shown proven efficacy in reducing mortality and remdesivir in improving clinical recovery, while many like hydroxychloroquine and convalescent plasma failed to meet expected efficacy. Given the severity of the disease, compassionate use of these drugs along with the symptomatic treatment and standard supportive care, is now being prescribed by the professionals. As it seems quite plausible that COVID-19 is here to stay for long, the efforts made towards finding an answer are still looking insufficient and require further research into greater depths [149]. Even if an effective solution is found, sooner or later emergence of resistance due to the highly mutable nature of the virus is inevitable. This warrants researchers to continue to race against time to formulate a better concoction and a vaccine to the SARS-CoV-2.

Again, we recommend against self-medication and reiterate the importance of seeking proper medical attention in line with local guidelines.

Acknowledgements We acknowledge Ram Lal Anand College for providing all the support required in compiling this review.

Author contributions All listed author(s) contributed equally.

Funding This research did not receive any specific grant from funding agencies in the public, commercial, or not-for-profit sectors.

\section{Compliance with ethical standards}

Conflict of interest The authors declare that they have no conflict of interest.

Ethics approval Not applicable.

Availability of data and material Not applicable.

Consent to participate and publication Not applicable.

\section{References}

1. Novel coronavirus-China, WHO. 2020. https://www.who.int/ csr/don/12-january-2020-novel-coronavirus-china/en/. Accessed 20 Apr 2020 
2. Huang C, Wang Y, Li X, et al. Clinical features of patients infected with 2019 novel coronavirus in Wuhan China. Lancet. 2020;395(10223):497-506. https://doi.org/10.1016/S0140 -6736(20)30183-5 ((published correction appears in Lancet. 2020 Jan 30)).

3. Wang D, Hu B, Hu C, et al. Clinical characteristics of 138 hospitalized patients with 2019 novel coronavirus-infected pneumonia in Wuhan China. JAMA. 2020;323(11):1061-9. https://doi. org/10.1001/jama.2020.1585 ((published online ahead of print, 2020 Feb 7)).

4. Feng Z, Li J, Yao S, et al. The use of adjuvant therapy in preventing progression to severe pneumonia in patients with coronavirus disease 2019: a multicenter data analysis. medRxiv. 2020. https ://doi.org/10.1101/2020.04.08.20057539.

5. Li Q, Guan X, Wu P, et al. Early transmission dynamics in Wuhan, China, of novel coronavirus-infected pneumonia. N Engl J Med. 2020;382(13):1199-207. https://doi.org/10.1056/NEJMo a2001316.

6. Wong CK, Lam CW, Wu AK, et al. Plasma inflammatory cytokines and chemokines in severe acute respiratory syndrome. Clin Exp Immunol. 2004;136(1):95-103. https://doi.org/10.111 1/j.1365-2249.2004.02415.x.

7. de Wit E, van Doremalen N, Falzarano D, Munster VJ. SARS and MERS: recent insights into emerging coronaviruses. Nat Rev Microbiol. 2016;14(8):523-34. https://doi.org/10.1038/nrmic ro.2016.81.

8. Kuba K, Imai Y, Rao S, et al. A crucial role of angiotensin converting enzyme 2 (ACE2) in SARS coronavirus-induced lung injury. Nat Med. 2005;11(8):875-9. https://doi.org/10.1038/ nm1267.

9. Eguchi S, Kawai T, Scalia R, Rizzo V. Understanding angiotensin II type 1 receptor signaling in vascular pathophysiology. Hypertension. 2018;71(5):804-10. https://doi.org/10.1161/HYPER TENSIONAHA.118.10266.

10. DiMasi JA, Grabowski HG, Hansen RW. Innovation in the pharmaceutical industry: new estimates of R\&D costs. J Health Econ. 2016;47:20-33. https://doi.org/10.1016/j.jhealeco.2016.01.012.

11. Pushpakom S, Iorio F, Eyers PA, et al. Drug repurposing: progress, challenges and recommendations. Nat Rev Drug Discov. 2019;18(1):41-58. https://doi.org/10.1038/nrd.2018.168.

12. Khailany RA, Safdar M, Ozaslan M. Genomic characterization of a novel SARS-CoV-2. Gene Rep. 2020;19:100682. https://doi. org/10.1016/j.genrep.2020.100682 ((published online ahead of print, 2020 Apr 16)).

13. Chen Y, Liu Q, Guo D. Emerging coronaviruses: genome structure, replication, and pathogenesis. J Med Virol. 2020;92:41823. https://doi.org/10.1002/jmv.25681.

14. Ziebuhr J, Snijder EJ, Gorbalenya AE. Virus-encoded proteinases and proteolytic processing in the Nidovirales. J Gen Virol. 2000;81(Pt 4):853-79. https://doi. org/10.1099/0022-1317-81-4-853.

15. Kamitani W, Narayanan K, Huang C, et al. Severe acute respiratory syndrome coronavirus nsp 1 protein suppresses host gene expression by promoting host mRNA degradation. Proc Natl Acad Sci USA. 2006;103(34):12885-90. https://doi.org/10.1073/ pnas.0603144103.

16. Narayanan $\mathrm{K}$, Huang $\mathrm{C}$, Lokugamage $\mathrm{K}$, et al. Severe acute respiratory syndrome coronavirus nsp1 suppresses host gene expression, including that of type I interferon, in infected cells. J Virol. 2008;82(9):4471-9. https://doi.org/10.1128/JVI.02472-07.

17. Neuman BW. Bioinformatics and functional analyses of coronavirus nonstructural proteins involved in the formation of replicative organelles. Antiviral Res. 2016;135:97-107. https://doi. org/10.1016/j.antiviral.2016.10.005.

18. Hurst KR, Ye R, Goebel SJ, Jayaraman P, Masters PS. An interaction between the nucleocapsid protein and a component of the replicase-transcriptase complex is crucial for the infectivity of coronavirus genomic RNA. J Virol. 2010;84(19):10276-88. https ://doi.org/10.1128/JVI.01287-10.

19. Hurst KR, Koetzner CA, Masters PS. Characterization of a critical interaction between the coronavirus nucleocapsid protein and nonstructural protein 3 of the viral replicase-transcriptase complex. J Virol. 2013;87(16):9159-72. https://doi.org/10.1128/ JVI.01275-13.

20. Harcourt BH, Jukneliene D, Kanjanahaluethai A, et al. Identification of severe acute respiratory syndrome coronavirus replicase products and characterization of papain-like protease activity. J Virol. 2004;78(24):13600-12. https://doi.org/10.1128/ JVI.78.24.13600-13612.2004.

21. Ratia K, Kilianski A, Baez-Santos YM, Baker SC, Mesecar A. Structural basis for the ubiquitin-linkage specificity and deISGylating activity of SARS-CoV papain-like protease. PLoS Pathog. 2014;10(5):e1004113. https://doi.org/10.1371/journ al.ppat.1004113 ((Published 2014 May 22)).

22. Saikatendu KS, Joseph JS, Subramanian V, et al. Structural basis of severe acute respiratory syndrome coronavirus ADPribose-1' -phosphate dephosphorylation by a conserved domain of nsP3. Structure. 2005;13(11):1665-75. https://doi. org/10.1016/j.str.2005.07.022.

23. Alhammad YMO, Kashipathy MM, Roy A, et al. The SARS-CoV-2 conserved macrodomain is a highly efficient ADP-ribosylhydrolase enzyme. bioRxiv. 2020. https://doi. org/10.1101/2020.05.11.089375.

24. Sakai Y, Kawachi K, Terada Y, Omori H, Matsuura Y, Kamitani W. Two-amino acids change in the nsp4 of SARS coronavirus abolishes viral replication. Virology. 2017;510:165-74. https:// doi.org/10.1016/j.virol.2017.07.019.

25. Thiel V, Ivanov KA, Putics Á, et al. Mechanisms and enzymes involved in SARS coronavirus genome expression. J Gen Virol. 2003;84(Pt 9):2305-15. https://doi.org/10.1099/vir.0.19424-0.

26. Yang H, Xie W, Xue X, et al. Design of wide-spectrum inhibitors targeting coronavirus main proteases. PLoS Biol. 2005;3(10):e324. https://doi.org/10.1371/journal.pbio.00303 24 ((published correction appears in PLoS Biol. 2005 Nov;3(11):e428)).

27. Angelini MM, Akhlaghpour M, Neuman BW, Buchmeier MJ. Severe acute respiratory syndrome coronavirus nonstructural proteins 3, 4, and 6 induce double-membrane vesicles. mBio. 2013;4(4):e00524-e613. https://doi.org/10.1128/mBio.00524-13 ((Published 2013 Aug 13)).

28. Cottam EM, Maier HJ, Manifava M, et al. Coronavirus nsp6 proteins generate autophagosomes from the endoplasmic reticulum via an omegasome intermediate. Autophagy. 2011;7(11):133547. https://doi.org/10.4161/auto.7.11.16642.

29. Zhai Y, Sun F, Li X, et al. Insights into SARS-CoV transcription and replication from the structure of the nsp7-nsp8 hexadecamer. Nat Struct Mol Biol. 2005;12(11):980-6. https://doi.org/10.1038/ nsmb999.

30. Imbert I, Guillemot JC, Bourhis JM, et al. A second, non-canonical RNA-dependent RNA polymerase in SARS coronavirus. EMBO J. 2006;25(20):4933-42. https://doi.org/10.1038/sj.emboj 7601368

31. Sutton G, Fry E, Carter L, et al. The nsp9 replicase protein of SARS-coronavirus, structure and functional insights. Structure. 2004;12(2):341-53. https://doi.org/10.1016/j.str.2004.01.016.

32. Miknis ZJ, Donaldson EF, Umland TC, Rimmer RA, Baric RS, Schultz LW. Severe acute respiratory syndrome coronavirus nsp9 dimerization is essential for efficient viral growth. J Virol. 2009;83(7):3007-18. https://doi.org/10.1128/JVI.01505-08.

33. New drug target found for COVID-19. Argonne National Laboratory. 2020. https://www.anl.gov/article/new-drug-target-found -for-covid19. Accessed 30 May 2020 
34. Chen Y, Su C, Ke M, et al. Biochemical and structural insights into the mechanisms of SARS coronavirus RNA ribose $2^{\prime}$-O-methylation by nsp16/nsp10 protein complex. PLoS Pathog. 2011;7(10):e1002294. https://doi.org/10.1371/journ al.ppat. 1002294.

35. Subissi L, Imbert I, Ferron F, et al. SARS-CoV ORF1bencoded nonstructural proteins 12-16: replicative enzymes as antiviral targets. Antiviral Res. 2014;101:122-30. https://doi. org/10.1016/j.antiviral.2013.11.006.

36. Ivanov KA, Ziebuhr J. Human coronavirus 229E nonstructural protein 13: characterization of duplex-unwinding, nucleoside triphosphatase, and RNA 5'-triphosphatase activities. J Virol. 2004;78(14):7833-8. https://doi.org/10.1128/ JVI.78.14.7833-7838.2004.

37. Chen Y, Cai H, Pan J, et al. Functional screen reveals SARS coronavirus nonstructural protein nsp14 as a novel cap N7 methyltransferase. Proc Natl Acad Sci USA. 2009;106(9):3484-9. https://doi.org/10.1073/pnas.0808790106

38. Bouvet M, Imbert I, Subissi L, Gluais L, Canard B, Decroly E. RNA 3'-end mismatch excision by the severe acute respiratory syndrome coronavirus nonstructural protein nsp10/ nsp14 exoribonuclease complex. Proc Natl Acad Sci USA. 2012;109(24):9372-7. https://doi.org/10.1073/pnas.1201130109.

39. Shannon A, Le NT, Selisko B, et al. Remdesivir and SARSCoV-2: structural requirements at both nsp12 RdRp and nsp14 Exonuclease active-sites. Antiviral Res. 2020;178:104793. https ://doi.org/10.1016/j.antiviral.2020.104793 ((published online ahead of print, $2020 \mathrm{Apr} 10)$ ).

40. Bhardwaj K, Guarino L, Kao CC. The severe acute respiratory syndrome coronavirus Nsp15 protein is an endoribonuclease that prefers manganese as a cofactor. J Virol. 2004;78(22):12218-24. https://doi.org/10.1128/JVI.78.22.12218-12224.2004.

41. Bouvet M, Debarnot C, Imbert I, et al. In vitro reconstitution of SARS-coronavirus mRNA cap methylation. PLoS Pathog. 2010;6(4):e1000863. https://doi.org/10.1371/ journal.ppat.1000863 ((published correction appears in PLoS Pathog. 2010;6(5). doi: 10.1371/annotation/ a0dde376-2eb1-4ce3-8887-d29f5ba6f162)).

42. Ivanov KA, Hertzig T, Rozanov M, et al. Major genetic marker of nidoviruses encodes a replicative endoribonuclease. Proc Natl Acad Sci USA. 2004;101(34):12694-9. https://doi.org/10.1073/ pnas.0403127101.

43. Satarker S, Nampoothiri M. Structural proteins in severe acute respiratory syndrome coronavirus-2. Arch Med Res. 2020. https ://doi.org/10.1016/j.arcmed.2020.05.012 ((published online ahead of print, 2020 May 25)).

44. Gralinski LE, Menachery VD. Return of the Coronavirus: 2019nCoV. Viruses. 2020;12(2):135. https://doi.org/10.3390/v1202 0135 ((Published 2020 Jan 24)).

45. Chen Y, Guo Y, Pan Y, Zhao ZJ. Structure analysis of the receptor binding of 2019-nCoV. Biochem Biophys Res Commun. 2020;525(1):135-40. https://doi.org/10.1016/j.bbrc.2020.02.071 ((published online ahead of print, 2020 Feb 17)).

46. Hoffmann M, Kleine-Weber H, Schroeder S, et al. SARS-CoV-2 cell entry depends on ACE2 and TMPRSS2 and is blocked by a clinically proven protease inhibitor. Cell. 2020;181(2):271-280. e8. https://doi.org/10.1016/j.cell.2020.02.052.

47. Ou X, Liu Y, Lei X, et al. Characterization of spike glycoprotein of SARS-CoV-2 on virus entry and its immune cross-reactivity with SARS-CoV. Nat Commun. 2020;11(1):1620. https://doi. org/10.1038/s41467-020-15562-9 ((Published 2020 Mar 27)).

48. Gupta MK, Vemula S, Donde R, Gouda G, Behera L, Vadde R. In-silico approaches to detect inhibitors of the human severe acute respiratory syndrome coronavirus envelope protein ion channel. J Biomol Struct Dyn. 2020. https://doi. org/10.1080/07391102.2020.1751300 ((published online ahead of print, 2020 Apr 15)).

49. Ye Y, Hogue BG. Role of the coronavirus E viroporin protein transmembrane domain in virus assembly. J Virol. 2007;81(7):3597-607. https://doi.org/10.1128/JVI.01472-06.

50. Neuman BW, Adair BD, Yoshioka C, et al. Supramolecular architecture of severe acute respiratory syndrome coronavirus revealed by electron cryomicroscopy. J Virol. 2006;80(16):7918-28. https://doi.org/10.1128/JVI.00645-06.

51. Huang Q, Yu L, Petros AM, et al. Structure of the N-terminal RNA-binding domain of the SARS CoV nucleocapsid protein. Biochemistry. 2004;43(20):6059-63. https://doi.org/10.1021/ bi036155b.

52. Ghofrani HA, Osterloh IH, Grimminger F. Sildenafil: from angina to erectile dysfunction to pulmonary hypertension and beyond. Nat Rev Drug Discov. 2006;5(8):689-702. https://doi. org/10.1038/nrd2030.

53. Wang M, Cao R, Zhang L, et al. Remdesivir and chloroquine effectively inhibit the recently emerged novel coronavirus (2019-nCoV) in vitro. Cell Res. 2020;30(3):269-71. https:// doi.org/10.1038/s41422-020-0282-0.

54. Sheahan TP, Sims AC, Graham RL, et al. Broad-spectrum antiviral GS-5734 inhibits both epidemic and zoonotic coronaviruses. Sci Transl Med. 2017;9(396):eaal3653. https://doi. org/10.1126/scitranslmed.aal3653.

55. Wu C, Liu Y, Yang Y, et al. Analysis of therapeutic targets for SARS-CoV-2 and discovery of potential drugs by computational methods. Acta Pharm Sin B. 2020. https://doi. org/10.1016/j.apsb.2020.02.008.

56. Grein J, Ohmagari N, Shin D, et al. Compassionate use of remdesivir for patients with severe COVID-19. N Engl J Med. 2020. https://doi.org/10.1056/NEJMoa2007016 ((published online ahead of print, 2020 Apr 10)).

57. Holshue ML, DeBolt C, Lindquist S, et al. First case of 2019 novel coronavirus in the United States. N Engl J Med. 2020;382(10):929-36. https://doi.org/10.1056/NEJMoa2001 191.

58. Wang Y, Zhang D, Du G, et al. Remdesivir in adults with severe COVID-19: a randomised, double-blind, placebo-controlled, multicentre trial. Lancet. 2020;395(10236):1569-78. https:// doi.org/10.1016/S0140-6736(20)31022-9 ((published correction appears in Lancet. 2020 May 30;395(10238):1694)).

59. Beigel JH, Tomashek KM, Dodd LE, et al. Remdesivir for the treatment of COVID-19-preliminary report. N Engl J Med. 2020. https://doi.org/10.1056/NEJMoa2007764.

60. Coronavirus (COVID-19) Update: FDA issues emergency use authorization for potential COVID-19 treatment. US FDA. 2020. https://www.fda.gov/news-events/press-announcements/coron avirus-covid-19-update-fda-issues-emergency-use-authorizat ion-potential-covid-19-treatment. Accessed 05 May 2020

61. Chu CM, Cheng VC, Hung IF, et al. Role of lopinavir/ritonavir in the treatment of SARS: initial virological and clinical findings. Thorax. 2004;59(3):252-6. https://doi.org/10.1136/thora x.2003.012658.

62. Cao B, Wang Y, Wen D, et al. A trial of lopinavir-ritonavir in adults hospitalized with severe COVID-19. N Engl J Med. 2020;382(19):1787-99. https://doi.org/10.1056/NEJMoa2001 282.

63. Li Y, Xie Z, Lin W, et al. An exploratory randomized controlled study on the efficacy and safety of lopinavir/ritonavir or arbidol treating adult patients hospitalized with mild/moderate COVID-19 (ELACOI). medRxiv. 2020. https://doi. org/10.1101/2020.03.19.20038984.

64. WHO discontinues hydroxychloroquine and lopinavir/ritonavir treatment arms for COVID-19. 2020. https://www.who.int/ news-room/detail/04-07-2020-who-discontinues-hydroxychl 
oroquine-and-lopinavir-ritonavir-treatment-arms-for-covid-19. Accessed 29 Sep 2020

65. No clinical benefit from use of lopinavir-ritonavir in hospitalised COVID-19 patients studied in RECOVERY-RECOVERY Trial. 2020. https://www.recoverytrial.net/news/no-clinical-benef it-from-use-of-lopinavir-ritonavir-in-hospitalised-covid-19-patie nts-studied-in-recovery. Accessed 29 Sep 2020

66. Blaising J, Polyak SJ, Pécheur EI. Arbidol as a broad-spectrum antiviral: an update. Antiviral Res. 2014;107:84-94. https://doi. org/10.1016/j.antiviral.2014.04.006.

67. Goldhill DH, Te Velthuis AJW, Fletcher RA, et al. The mechanism of resistance to favipiravir in influenza. Proc Natl Acad Sci USA. 2018;115(45):11613-8. https://doi.org/10.1073/ pnas. 1811345115.

68. Furuta Y, Komeno T, Nakamura T. Favipiravir (T-705), a broad spectrum inhibitor of viral RNA polymerase. Proc Jpn Acad Ser B Phys Biol Sci. 2017;93(7):449-63. https://doi.org/10.2183/ pjab.93.027.

69. Elfiky AA. SARS-CoV-2 RNA dependent RNA polymerase (RdRp) targeting: an in silico perspective. J Biomol Struct Dyn. 2020;5:1-9. https://doi.org/10.1080/07391102.2020.1761882 ((published online ahead of print, 2020 May 6)).

70. Chen C, Zhang Y, Huang J, et al. Favipiravir versus Arbidol for COVID-19: a randomized clinical trial. medRxiv. 2020. https:// doi.org/10.1101/2020.03.17.20037432.

71. Liu Q, Fang X, Tian L, et al. The effect of Arbidol Hydrochloride on reducing mortality of Covid-19 patients: a retrospective study of real world date from three hospitals in Wuhan. medRxiv. 2020. https://doi.org/10.1101/2020.04.11.20056523.

72. Zhou Y, He X, Zhang J, et al. Prolonged SARS-CoV-2 Viral shedding in patients with COVID-19 was associated with delayed initiation of arbidol treatment: a retrospective cohort study. medRxiv. 2020. https://doi.org/10.1101/2020.06.09.20076646.

73. Seiwert SD, Andrews SW, Jiang Y, et al. Preclinical characteristics of the hepatitis $\mathrm{C}$ virus NS3/4A protease inhibitor ITMN-191 (R7227). Antimicrob Agents Chemother. 2008;52(12):4432-41. https://doi.org/10.1128/AAC.00699-08.

74. Wei L, Shang J, Ma Y, et al. Efficacy and safety of 12-week interferon-based danoprevir regimen in patients with genotype 1 chronic hepatitis C. J Clin Transl Hepatol. 2019;7(3):221-5. https://doi.org/10.14218/JCTH.2019.00018.

75. Beck BR, Shin B, ChoiChu Y, et al. Predicting commercially available antiviral drugs that may act on the novel coronavirus (2019-nCoV), Wuhan, China through a drug-target interaction deep learning model. BioRxiv. 2020. https://doi. org/10.1101/2020.01.31.929547.

76. Chen H, Zhang Z, Wang L, et al. First clinical study using $\mathrm{HCV}$ protease inhibitor danoprevir to treat naive and experienced COVID-19 Patients. medRxiv. 2020. https://doi. org/10.1101/2020.03.22.20034041

77. Graci JD, Cameron CE. Mechanisms of action of ribavirin against distinct viruses. Rev Med Virol. 2006;16(1):37-48. https ://doi.org/10.1002/rmv.483.

78. Crotty S, Cameron CE, Andino R. RNA virus error catastrophe: direct molecular test by using ribavirin. Proc Natl Acad Sci USA. 2001;98(12):6895-900. https://doi.org/10.1073/pnas.111085598.

79. Manns MP, McHutchison JG, Gordon SC, et al. Peginterferon alfa- $2 b$ plus ribavirin compared with interferon alfa- $2 b$ plus ribavirin for initial treatment of chronic hepatitis $\mathrm{C}$ : a randomised trial. Lancet. 2001;358(9286):958-65. https://doi.org/10.1016/ s0140-6736(01)06102-5.

80. Bausch Health Initiates VIRAZOLE® (Ribavirin for Inhalation Solution, USP) clinical study in patients with COVID- 19 . Bausch Health. 2020. https://ir.bauschhealth.com/news-relea ses/2020/04-13-2020-120008693. Accessed 28 Apr 2020
81. Mo Y, Fisher D. A review of treatment modalities for middle east respiratory syndrome. J Antimicrob Chemother. 2016;71(12):3340-50. https://doi.org/10.1093/jac/dkw338.

82. Lu H. Drug treatment options for the 2019-new coronavirus (2019-nCoV). Biosci Trends. 2020;14(1):69-71. https://doi. org/10.5582/bst.2020.01020.

83. Hung IF-N, Lung K-C, Tso EY-K, et al. Triple combination of interferon beta- $1 \mathrm{~b}$, lopinavir-ritonavir, and ribavirin in the treatment of patients admitted to hospital with COVID-19: an openlabel, randomised, phase 2 trial. Lancet. 2020;395(10238):1695704. https://doi.org/10.1016/S0140-6736(20)31042-4.

84. Meyer SD, Bojkova D, Cinati J, et al. Lack of antiviral activity of darunavir against SARS-CoV-2. medRxiv. 2020. https://doi. org/10.1101/2020.04.03.20052548.

85. Lack of evidence to support use of darunavir-based treatments for SARS-CoV-2. Johnson \& Johnson. 2020. https://www.jnj. com/lack-of-evidence-to-support-darunavir-based-hiv-treatments -for-coronavirus. Accessed 29 April 2020

86. Bourinbaiar AS, Fruhstorfer EC. The effect of histamine type 2 receptor antagonists on human immunodeficiency virus (HIV) replication: identification of a new class of antiviral agents. Life Sci. 1996. https://doi.org/10.1016/s0024-3205(96)00553-x.

87. Freedberg DE, Conigliaro J, Sobieszczyk ME, et al. Famotidine use is associated with improved clinical outcomes in hospitalized COVID-19 patients: a propensity score matched retrospective cohort study. medRxiv. 2020. https://doi. org/10.1101/2020.05.01.20086694.

88. Hogan RB II, Hogan RB III, Cannon T, et al. Dual-histamine receptor blockade with cetirizine-famotidine reduces pulmonary symptoms in COVID-19 patients. Pulm Pharmacol Ther. 2020;63:101942. https://doi.org/10.1016/j.pupt.2020.101942.

89. Fox RI. Mechanism of action of hydroxychloroquine as an antirheumatic drug. Semin Arthritis Rheum. 1993;23(2 Suppl 1):82-91. https://doi.org/10.1016/s0049-0172(10)80012-5.

90. Al-Bari MAA. Targeting endosomal acidification by chloroquine analogs as a promising strategy for the treatment of emerging viral diseases. Pharmacol Res Perspect. 2017;5(1):e00293. https ://doi.org/10.1002/prp2.293 ((Published 2017 Jan 23)).

91. Coronavirus (COVID-19) update: FDA revokes emergency use authorization for chloroquine and hydroxychloroquine. US FDA. 2020. https://www.fda.gov/news-events/press-announcements/ coronavirus-covid-19-update-fda-revokes-emergency-use-autho rization-chloroquine-and. Accessed 25 June 2020

92. Gautret P, Lagier JC, Parola P, et al. Hydroxychloroquine and azithromycin as a treatment of COVID-19: results of an openlabel non-randomized clinical trial. Int J Antimicrob Agents. 2020. https://doi.org/10.1016/j.ijantimicag.2020.105949 ((published online ahead of print, 2020 Mar 20)).

93. Chen Z, Hu J, Zhang Z, et al. Efficacy of hydroxychloroquine in patients with COVID-19: results of a randomized clinical trial. medRxiv. 2020. https://doi.org/10.1101/2020.03.22.20040758.

94. Molina JM, Delaugerre C, Le Goff J, et al. No evidence of rapid antiviral clearance or clinical benefit with the combination of hydroxychloroquine and azithromycin in patients with severe COVID-19 infection. Med Mal Infect. 2020;50(4):384. https:// doi.org/10.1016/j.medmal.2020.03.006.

95. Borba MGS, Val FA, Sampaio VS, et al. Chloroquine diphosphate in two different dosages as adjunctive therapy of hospitalized patients with severe respiratory syndrome in the context of coronavirus (SARS-CoV-2) infection: preliminary safety results of a randomized, double-blinded, phase IIb clinical trial (CloroCovid-19 Study). medRxiv. 2020. https://doi. org/10.1101/2020.04.07.20056424.

96. Tang W, Cao Z, Han M, et al. Hydroxychloroquine in patients mainly with mild to moderate COVID-19: an open-label, 
randomized, controlled trial. medRxiv. 2020. https://doi. org/10.1101/2020.04.10.20060558.

97. Mahevas M, Tran VT, Roumier M, et al. No evidence of clinical efficacy of hydroxychloroquine in patients hospitalized for COVID-19 infection with oxygen requirement: results of a study using routinely collected data to emulate a target trial. medRxiv. 2020. https://doi.org/10.1101/2020.04.10.20060699.

98. WHO Director-General's opening remarks at the media briefing on COVID-19-25 May 2020. WHO. 2020. https://www. who.int/dg/speeches/detail/who-director-general-s-openingremarks-at-the-media-briefing-on-covid-19---25-may-2020. Accessed 31 May 2020

99. WHO Emergencies Press Conference on coronavirus disease outbreak-03 June 2020. WHO. 2020. https://www.who.int/ docs/default-source/coronaviruse/transcripts/who-audio-emerg encies-coronavirus-press-conference-03jun2020.pdf?sfvrs $\mathrm{n}=2338 \mathrm{e} 5 \mathrm{ce} \_0$. Accessed 05 June 2020

100. Davies R, Choy E. Clinical experience of IL-6 blockade in rheumatic diseases-implications on IL-6 biology and disease pathogenesis. Semin Immunol. 2014;26(1):97-104. https://doi. org/10.1016/j.smim.2013.12.002.

101. Gabay C, Emery P, van Vollenhoven R, et al. Tocilizumab monotherapy versus adalimumab monotherapy for treatment of rheumatoid arthritis (ADACTA): a randomised, double-blind, controlled phase 4 trial. Lancet. 2013;381(9877):1541-50. https://doi.org/10.1016/S0140-6736(13)60250-0 (([published correction appears in Lancet. 2013 Dec 7;382(9908):1878] [published correction appears in Lancet. 2013 May 4;381(9877):1540. Dosage error in article text])).

102. Xu X, Han M, Li T, et al. Effective treatment of severe COVID19 patients with tocilizumab. Proc Natl Acad Sci USA. 2020;117(20):10970-5. https://doi.org/10.1073/pnas.20056 15117.

103. Quartuccio L, Sonaglia A, McGonagle D, et al. Profiling COVID-19 pneumonia progressing into the cytokine storm syndrome: results from a single Italian Centre study on tocilizumab versus standard of care. medRxiv. 2020. https://doi. org/10.1101/2020.05.01.20078360.

104. Roumier M, Paule R, Groh M, Vallee A, Ackermann F. Interleukin-6 blockade for severe COVID-19. medRxiv. 2020. https ://doi.org/10.1101/2020.04.20.20061861.

105. Wadud N, Ahmed N, Shergil MM, et al. Improved survival outcome in SARs-CoV-2 (COVID-19) Acute Respiratory Distress Syndrome patients with Tocilizumab administration. medRxiv. 2020. https://doi.org/10.1101/2020.05.13.20100081.

106. Rosas I, Bräu N, Waters M, et al. Tocilizumab in hospitalized patients with COVID-19 pneumonia. medRxiv. 2020. https:// doi.org/10.1101/2020.08.27.20183442.

107. Tay MY, Fraser JE, Chan WK, et al. Nuclear localization of dengue virus (DENV) 1-4 non-structural protein 5; protection against all 4 DENV serotypes by the inhibitor Ivermectin. Antiviral Res. 2013;99(3):301-6. https://doi.org/10.1016/j. antiviral.2013.06.002.

108. Wagstaff KM, Sivakumaran H, Heaton SM, Harrich D, Jans DA. Ivermectin is a specific inhibitor of importin $\alpha / \beta$-mediated nuclear import able to inhibit replication of HIV-1 and dengue virus. Biochem J. 2012;443(3):851-6. https://doi.org/10.1042/ BJ20120150.

109. Yang SNY, Atkinson SC, Wang C, et al. The broad spectrum antiviral ivermectin targets the host nuclear transport importin $\alpha / \beta 1$ heterodimer. Antiviral Res. 2020;177:104760. https://doi. org/10.1016/j.antiviral.2020.104760.

110. Caly L, Druce JD, Catton MG, Jans DA, Wagstaff KM. The FDA-approved drug ivermectin inhibits the replication of SARS-CoV-2 in vitro. Antiviral Res. 2020;178:104787. https ://doi.org/10.1016/j.antiviral.2020.104787 ((published online ahead of print, 2020 Apr 3))

111. Bray M, Rayner C, Noël F, Jans D, Wagstaff K. Ivermectin and COVID-19: a report in antiviral research, widespread interest, an FDA warning, two letters to the editor and the authors' responses. Antiviral Res. 2020;178:104805. https://doi.org/10.1016/j.antiv iral.2020.104805 ((published online ahead of print, 2020 Apr 21)).

112. Paz LAG, Lossada CA, Moncayo LS, et al. Molecular docking and molecular dynamic study of two viral proteins associated with SARS-CoV-2 with ivermectin. Preprints 2020; 2020040334. https://doi.org/10.20944/preprints202004.0334.v1

113. Chaccour C, Hammann F, Ramón-García S, Rabinovich NR. Ivermectin and novel coronavirus disease (COVID19): keeping rigor in times of urgency. Am J Trop Med Hyg. 2020;102(6):1156-7. https://doi.org/10.4269/ajtmh.20-0271 ((published online ahead of print, 2020 Apr 16)).

114. Rajter JC, Sherman M, Fatteh N, Vogel F, Sacks J, Rajter J-J. ICON (Ivermectin in COvid Nineteen) study: use of ivermectin is associated with lower mortality in hospitalized patients with COVID19. medRxiv. 2020. https://doi. org/10.1101/2020.06.06.20124461.

115. Gorial FI, Mashhadani S, Sayaly HM, et al. Effectiveness of ivermectin as add-on therapy in COVID-19 management (pilot trial). medRxiv. 2020. https://doi.org/10.1101/2020.07.07.20145979.

116. Bangladesh medical team says Ivermectin with antibiotic Doxycycline works to treat COVID-19 patients. 2020. https://www. firstpost.com/health/bangladesh-medical-team-says-ivermectin -with-antibiotic-doxycycline-works-to-treat-covid-19-patients8381321.html. Accessed 01 June 2020

117. Chroboczek T, Lacoste M, Wackenheim C, et al. Beneficial effect of corticosteroids in severe COVID-19 pneumonia: a propensity score matching analysis. medRxiv. 2020. https://doi. org/10.1101/2020.05.08.20094755.

118. Fadel R, Morrison A, Vahia A, et al. Early short course corticosteroids in hospitalized patients with COVID-19. medRxiv. 2020. https://doi.org/10.1101/2020.05.04.20074609.

119. Fernandez-Cruz A, Ruiz-Antoran B, Munoz-Gomez A, et al. Impact of glucocorticoid treatment in sars-cov-2 infection mortality: a retrospective controlled cohort study. medRxiv. 2020. https://doi.org/10.1101/2020.05.22.20110544.

120. Wang Y, Jiang W, He Q, et al. Early, low-dose and short-term application of corticosteroid treatment in patients with severe COVID-19 pneumonia: single-center experience from Wuhan, China. medRxiv. 2020. https://doi.org/10.1101/2020.03.06.20032 342.

121. Lu X, Chen T, Wang Y, et al. Adjuvant corticosteroid therapy for critically ill patients with COVID-19. medRxiv. 2020. https ://doi.org/10.1101/2020.04.07.20056390.

122. Wang D, Wang J, Jiang Q, et al. No clear benefit to the use of corticosteroid as treatment in adult patients with coronavirus disease 2019: a retrospective cohort study. medRxiv. 2020. https:// doi.org/10.1101/2020.04.21.20066258.

123. Rhen T, Cidlowski JA. Antiinflammatory action of glucocorticoids-new mechanisms for old drugs. N Engl J Med. 2005;353(16):1711-23. https://doi.org/10.1056/NEJMra050541.

124. World Health Organization (2020) Clinical management of severe acute respiratory infection (SARI) when COVID-19 disease is suspected: interim guidance, 13 March 2020. World Health Organization. https://apps.who.int/iris/handle/10665 1331446. License: CC BY-NC-SA 3.0 IGO. Accessed 05 April 2020.

125. Low-cost dexamethasone reduces death by up to one third in hospitalised patients with severe respiratory complications of COVID-19. 2020. http://www.ox.ac.uk/ 
news/2020-06-16-low-cost-dexamethasone-reduces-death-onethird-hospitalised-patients-severe. Accessed 20 June 2020

126. Coronavirus breakthrough: dexamethasone is first drug shown to save lives. https://www.nature.com/articles/d41586-020-01824 -5 . Accessed 20 June 2020

127. The RECOVERY Collaborative Group. Dexamethasone in hospitalized patients with COVID-19-preliminary report. N Engl J Med. 2020. https://doi.org/10.1056/nejmoa2021436.

128. Corral L, Bahamonde A, Revillas FAD, et al. GLUCOCOVID: a controlled trial of methylprednisolone in adults hospitalized with COVID-19 pneumonia. medRxiv. 2020. https://doi. org/10.1101/2020.06.17.20133579.

129. Salton F, Confalonieri P, Santus P, et al. Prolonged low-dose methylprednisolone in patients with severe COVID-19 pneumonia. medRxiv. 2020. https://doi.org/10.1101/2020.06.17.20134 031 .

130. The WHO Rapid Evidence Appraisal for COVID-19 Therapies (REACT) Working Group. Association between administration of systemic corticosteroids and mortality among critically ill patients with COVID-19: a meta-analysis. JAMA. 2020. https:// doi.org/10.1001/jama.2020.17023.

131. Eibl MM. History of immunoglobulin replacement. Immunol Allergy Clin N Am. 2008;28(4):737-8. https://doi.org/10.1016/j. iac.2008.06.004.

132. Piechotta V, Chai KL, Valk SJ, et al. Convalescent plasma or hyperimmune immunoglobulin for people with COVID-19: a living systematic review. Cochrane Database Syst Rev. 2020. https ://doi.org/10.1002/14651858.CD013600.pub2.

133. Gharbharan A, Jordans CCE, GeurtsvanKessel C, et al. Convalescent plasma for COVID-19. A randomized clinical trial. medRxiv. 2020. https://doi.org/10.1101/2020.07.01.20139857.

134. Agarwal A, Mukherjee A, Kumar G, et al. Convalescent plasma in the management of moderate COVID-19 in India: An open-label parallel-arm phase II multicentre randomized controlled trial (PLACID Trial). medRxiv. 2020. https://doi. org/10.1101/2020.09.03.20187252.

135. Mansourabadi AH, Sadeghalvad M, Mohammadi-Motlagh HR, Rezaei N. The immune system as a target for therapy of SARSCoV-2: a systematic review of the current immunotherapies for COVID-19. Life Sci. 2020;258:118185. https://doi.org/10.1016/j. lfs.2020.118185.

136. Beck BR, Shin B, Choi Y, Park S, Kang K. Predicting commercially available antiviral drugs that may act on the novel coronavirus (SARS-CoV-2) through a drug-target interaction deep learning model. Comput Struct Biotechnol J. 2020;18:784-90. https://doi.org/10.1016/j.csbj.2020.03.025 ((Published 2020 Mar 30))

137. Xu Z, Peng C, Shi Y, et al. Nelfinavir was predicted to be a potential inhibitor of 2019-nCov main protease by an integrative approach combining homology modelling, molecular docking and binding free energy calculation. bioRxiv. 2020. https://doi. org/10.1101/2020.01.27.921627.

138. Helenius A, Aebi M. Intracellular functions of $\mathrm{N}$-linked glycans. Science. 2001;291(5512):2364-9. https://doi.org/10.1126/scien ce.291.5512.2364.
139. Fukushi M, Yoshinaka Y, Matsuoka Y, et al. Monitoring of S protein maturation in the endoplasmic reticulum by calnexin is important for the infectivity of severe acute respiratory syndrome coronavirus. J Virol. 2012;86(21):11745-53. https://doi org/10.1128/JVI.01250-12.

140. Rajasekharan S, Bonotto RM, Kazungu Y, et al. Repurposing of miglustat to inhibit the coronavirus severe acquired respiratory syndrome SARS-CoV-2. bioRxiv. 2020. https://doi. org/10.1101/2020.05.18.101691.

141. Balasubramaniam M, Reis RJS. Computational target-based drug repurposing of elbasvir, an antiviral drug predicted to bind multiple SARS-CoV-2 proteins. Preprint. ChemRxiv. 2020; https:// doi.org/10.26434/chemrxiv.12084822.v2. Published 2020 Apr 8. https://doi.org/10.26434/chemrxiv.12084822

142. Sheahan TP, Sims AC, Zhou S, et al. An orally bioavailable broad-spectrum antiviral inhibits SARS-CoV-2 in human airway epithelial cell cultures and multiple coronaviruses in mice. Sci Transl Med. 2020;12(541):eab5883. https://doi.org/10.1126/scitr anslmed.abb5883.

143. Wu Y, Guo C, Tang L, Hong Z, Zhou J, Dong X, et al. Prolonged presence of SARS-CoV-2 viral RNA in faecal samples. Lancet Gastroenterol Hepatol. 2020. https://doi.org/10.1016/S2468 $-1253(20) 30083-2$

144. Chu DK, Akl EA, Duda S, et al. Physical distancing, face masks, and eye protection to prevent person-to-person transmission of SARS-CoV-2 and COVID-19: a systematic review and meta-analysis. Lancet. 2020;395(10242):1973-87. https://doi. org/10.1016/S0140-6736(20)31142-9.

145. Saha A, Sharma AR, Bhattacharya M, et al. Probable molecular mechanism of remdesivir for the treatment of COVID-19: need to know more. Arch Med Res. 2020;51(6):585-6. https://doi. org/10.1016/j.arcmed.2020.05.001.

146. Saha A, Sharma AR, Bhattacharya M, et al. Tocilizumab: a therapeutic option for the treatment of cytokine storm syndrome in COVID-19. Arch Med Res. 2020;51(6):595-7. https://doi. org/10.1016/j.arcmed.2020.05.009.

147. Imai M, Iwatsuki-Horimoto K, Hatta M, et al. Syrian hamsters as a small animal model for SARS-CoV-2 infection and countermeasure development. Proc Natl Acad Sci. 2020;117(28):16587_ 95. https://doi.org/10.1073/pnas.2009799117.

148. Kaur SP, Gupta V. COVID-19 Vaccine: a comprehensive status report. Virus Res. 2020;288:198114. https://doi.org/10.1016/j. virusres.2020.198114.

149. Chakraborty C, Sharma AR, Sharma G, et al. Extensive partnership, collaboration, and teamwork is required to stop the COVID-19 outbreak. Arch Med Res. 2020;51(7):728-30. https ://doi.org/10.1016/j.arcmed.2020.05.021.

Publisher's Note Springer Nature remains neutral with regard to jurisdictional claims in published maps and institutional affiliations. 